\title{
The quantity theory of stock prices
}

\section{Xiaojing Song, Thu Phuong Truong, Mark Tippett \& John van der Burg}

To cite this article: Xiaojing Song, Thu Phuong Truong, Mark Tippett \& John van der Burg (2022): The quantity theory of stock prices, The European Journal of Finance, DOI: 10.1080/1351847X.2021.2002705

To link to this article: https://doi.org/10.1080/1351847X.2021.2002705

+ View supplementary material $\widetilde{ }$

曲 Published online: 19 Jan 2022.

Submit your article to this journal 전

Q View related articles ๘

View Crossmark data \lceil 


\title{
The quantity theory of stock prices
}

\author{
Xiaojing Song ${ }^{a}$, Thu Phuong Truong ${ }^{b}$, Mark Tippett ${ }^{c}$ and John van der Burg ${ }^{b, d}$ \\ ${ }^{a}$ Newcastle University Business School, Newcastle upon Tyne, UK; ${ }^{b}$ Wellington School of Business and Government, Victoria \\ University of Wellington, Wellington, New Zealand; ' $S$ School of Business and Economics, Loughborough University, Leicestershire,

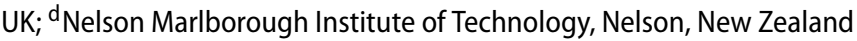

\begin{abstract}
We determine the implications of the Modern Quantity Theory of Money for the nominal pricing of equity stocks. Our analysis is compatible with the hypothesis that the ratio of the quantity of money in circulation to a comprehensive index of stock prices evolves in terms of an elastic (that is, mean reverting) random walk. Using annual U.S. data covering the period from 1871 until 2018 shows that the 'half-life' of the period it takes for the money to stock price ratio to converge towards its long-run mean, is around fifteen years. Our empirical analysis also shows that unexpected inflation has a disruptive impact on the output and investment decisions implemented by firms and leads to an increase in the money to stock price ratio (equivalently, the stock price index falls relative to the quantity of money in circulation). We also develop a framework for determining how economic agents can rebalance their investment portfolios in response to disequilibria in the money to stock price ratio and thereby maximise the expected discounted utility obtained from their future consumption.
\end{abstract}

\section{ARTICLE HISTORY}

Received 13 May 2021

Accepted 25 October 2021

\section{KEYWORDS}

Modern Quantity Theory of Money; money to stock price ratio; elastic random walk; Hamilton-Jacobi-Bellman equation

\section{JEL CODES:}

$\mathrm{C} 22 ; \mathrm{G} 12 ; \mathrm{E} 41$

\section{Introduction}

A central theme of Friedman's (1956) restatement of the Quantity Theory of Money - otherwise known as the Modern Quantity Theory of Money (Patinkin 1972) - is that the demand for money hinges on the returns available from a variety of assets such as bonds, equities, physical goods and human capital, amongst others. By including a range of assets alternative to money, Friedman (1956) shows how the simple money-to-bonds transmission mechanism of Keynesian economics fails to capture the pervasive effects that monetary policy can have on economic activity (Cagan 1972). The underlying assumption on which Friedman's (1956) analysis is based is that unexpected disturbances in monetary policy induce disequilibria in asset markets by driving a wedge between actual and desired monetary holdings. Economic agents respond to this by rebalancing their asset portfolios to restore monetary balances to their desired levels. This transmits the effects of unexpected changes in monetary policy into other markets, including the bond markets, equities, output markets and investments made by economic agents in human capital. ${ }^{1}$ Moreover, the period over which this rebalancing of asset portfolios occurs is an issue that can only be resolved empirically but is normally taken to be long, variable, and unpredictable (Batini and Nelson 2002). In this paper we develop the implications of the Modern Quantity Theory of Money for the nominal pricing of equity stocks.

Our analysis opens in the next section with a short summary of monetary demand under the Modern Quantity Theory of Money. However, since the Modern Quantity Theory of Money encompasses only limited information about how market disequilibria are eliminated (Friedman 1970; Lucas 1996), in section 3 we examine the adjustment dynamics associated with the money to stock price ratio. ${ }^{2}$ Here, we follow received wisdom in basing the evolution of the money supply on the standard Geometric Brownian Motion (Kumhof 
and Van Nieuwerburgh 2002, 8). In contrast, we take the evolution of the stock price index to be described by a transformed interpretation of the Uhlenbeck and Ornstein (1930) process - one of the most widely applied stochastic processes in financial economics (Gibson and Schwartz 1990; Barndorff-Nielsen and Shephard 2001; Hong and Satchell 2012). We demonstrate that under these specifications, the money to stock price ratio evolves in terms of an elastic (that is, mean reverting) random walk. In section 4 we use annual U.S. data covering the period from 1871 until 2018 to show that the 'half-life' of the period it takes for the money to stock price ratio to converge towards its long-run equilibrium value is around fifteen years. Here, however, Friedman $(1977,456)$ and Fama (1981) amongst others ${ }^{3}$ demonstrate that the inflationary implications of unexpected variations in monetary policy can have a disruptive and often, severe impact on the output and investment decisions implemented by firms. In section 5 we demonstrate how this hypothesis is supported by our empirical analysis which models prices and inflation in terms of the U.S. Consumer Price Index (CPI) and shows how unexpected inflation is invariably accompanied by an increase in the money to stock price ratio. In section 6 we broaden the Friedman (1956) analysis of the demand for money by developing optimal portfolio selection and intertemporal consumption rules for an economic agent whose income is generated by the returns from an investment portfolio comprised of the stock price index and a complementary holding of money. Section 7 contains our summary conclusions.

Our analysis makes several original contributions to the literature. Foremost amongst these is that we obtain a closed form expression for the index of stock prices which includes both the expected and stochastic components of the rate of increase in the money supply as explicit arguments. This in turn provides an explicit link between the quantity of money in circulation and the absolute level of stock prices and allows one to determine the impact that unexpected variations in monetary policy will have on the risk (that is, volatility) and returns associated with investments in the stock index. We also present a framework for determining how economic agents can exploit disequilibria in the money to stock price ratio (as, for example, because of quantitative easing) to rebalance their investment portfolios and thereby maximise the expected discounted utility obtained from their future consumption.

\section{Modern Quantity Theory of Money}

Friedman $(1956,10)$ argues that the demand for money, $M(t)$, is a relatively stable function, $f(\cdot)$, of a small number of determining variables; namely: ${ }^{4}$

$$
M=f\left(I, r_{b}, r_{e}, \frac{1}{I} \frac{d I}{d t}, v, W, u\right)
$$

where $I$ is an index of the prices of goods and services in the economy, $r_{b}$ is the return on bonds ${ }^{5}, r_{e}$ is the return on equities, $\frac{1}{I} \frac{d I}{d t}$ is the infinitesimal rate of inflation, $v$ is the ratio of income from non-human wealth to income from human wealth ${ }^{6}, W$ is the economic agent's 'wealth, including money and physical capital goods' (Friedman 1956, 11; Friedman 1957) and $u$ represents changes in tastes and preferences over time. Moreover, Friedman $(1956,11)$ notes that if the unit [of currency] in which prices and money income are expressed is changed, the amount of money demanded should change proportionately. More technically, equation (1) must be regarded as homogeneous of the first degree in $I$ and $W \ldots$, or:

$$
\lambda M=\lambda f\left(I, r_{b}, r_{e}, \frac{1}{I} \frac{d I}{d t}, v, W, u\right)=f\left(\lambda I, r_{b}, r_{e}, \frac{1}{I} \frac{d I}{d t}, v, \lambda W, u\right)
$$

for all values of the parameter, $\lambda$. Now, let $P(t)$ represent the value of a comprehensive index of stock prices and set $\lambda=\frac{1}{P}$. It then follows that the equilibrium money to stock price ratio will be given by:

$$
\frac{M}{P}=f\left(\frac{I}{P}, r_{b}, r_{e}, \frac{1}{I} \frac{d I}{d t}, v, \frac{W}{P}, u\right)
$$


Here, Friedman $(1956,5-6)$ also notes, however, that $\frac{1}{r_{e}}$ will 'be the price of an equity promising to pay $\$ 1$ per year if the price level does not change, or to pay:

$$
P(t)=\frac{I(t)}{I(0) r_{e}(t)}
$$

if the price level varies according to $I(t)^{\prime}$. This in turn will mean that the money to stock price ratio will be independent of the unit of currency in which the components of the ratio are expressed. Moreover, it also follows from these results that if one normalises the price index so that $I(0)=1$, the return on equity may be presented as $r_{e}(t)=\frac{I(t)}{P(t)}$. Finally, Friedman $(1956,9)$ notes that in 'order to give the theory empirical content', the ratio of income from non-human wealth to income from human wealth $(v)$ must be taken as a 'given' whilst it will also have to be 'supposed that tastes [and preferences, $u$ ] are constant over significant stretches of space and time'. Bringing these factors together will mean that under the Friedman (1956) interpretation of the Modern Quantity Theory of Money, empirical specifications of the money to stock price ratio will reduce to a function of the following four variables:

$$
\frac{M}{P}=f\left(r_{b}, r_{e}, \frac{1}{I} \frac{d I}{d t}, \frac{W}{P}\right)
$$

Note, however, how the above formulation provides a largely static description of the evolution of the money to stock price ratio - that is, it encompasses only limited information about the dynamics of how the money to stock price ratio converges towards its equilibrium value (Friedman 1970; Lucas 1996). As previously noted, the underlying assumption is that unexpected disturbances in monetary policy induce disequilibria in asset markets. Economic agents will then restore monetary balances to desired levels by rebalancing their asset portfolios. We now examine this issue in further detail by modelling the adjustment dynamics associated with the money to stock price ratio.

\section{Adjustment dynamics}

As previously noted, the money supply, $M(t)$, at time $t$ is defined in terms of the M2 monetary aggregate for the U.S. economy whilst the index of stock prices, $P(t)$, is defined in terms of the S\&P Composite Index. It then follows that the money to stock price ratio, $g(t)$, at time $t$ is determined as:

$$
g(t) \equiv \frac{M(t)}{P(t)}
$$

Here, one can use Itô's formula to determine infinitesimal increments in the money to stock price ratio, as follows (Tippett 1990, 85):

$$
\begin{gathered}
d g(t)=\frac{\partial g(t)}{\partial M(t)} d M(t)+\frac{\partial g(t)}{\partial P(t)} d P(t) \\
+\frac{1}{2}\left\{\frac{\partial^{2} g(t)}{\partial M(t)^{2}}[d M(t)]^{2}+2 \frac{\partial^{2} g(t)}{\partial M(t) \partial P(t)} d M(t) d P(t)+\frac{\partial^{2} g(t)}{\partial P(t)^{2}}[d P(t)]^{2}\right\}
\end{gathered}
$$

where:

$$
\frac{\partial g(t)}{\partial M(t)}=\frac{1}{P(t)} \quad \frac{\partial g(t)}{\partial P(t)}=-\frac{M(t)}{P(t)^{2}} \quad \frac{\partial^{2} g(t)}{\partial M(t)^{2}}=0 \quad \frac{\partial^{2} g(t)}{\partial M(t) \partial P(t)}=-\frac{1}{P(t)^{2}} \quad \frac{\partial^{2} g(t)}{\partial P(t)^{2}}=2 \frac{M(t)}{P(t)^{3}}
$$

Substituting the above partial derivatives into equation (5) will then show that infinitesimal proportionate variations in the money to stock price ratio will evolve in terms of the following expression:

$$
\frac{d g(t)}{g(t)}=\frac{d M(t)}{M(t)}-\frac{d P(t)}{P(t)}+\left[\frac{d P(t)}{P(t)}\right]^{2}-\frac{d M(t)}{M(t)} \frac{d P(t)}{P(t)}
$$


Now, suppose one follows conventional practice in assuming that the money supply evolves in terms of the Geometric Brownian Motion (Kumhof and Van Nieuwerburgh 2002, 8), or:

$$
\frac{d M(t)}{M(t)}=\alpha_{1} d t+d z_{1}(t)
$$

where $\alpha_{1}$ is the expected rate of growth (per unit time) in the money supply and $d z_{1}(t)$ is a white noise process with variance parameter $\sigma_{1}^{2}$. It is well known that the unique (that is, strong) solution of the differential equation (7) takes the form (Karlin and Taylor 1981, 358-360):

$$
M(t)=M(0) \exp \left\{\left(\alpha_{1}-\frac{1}{2} \sigma_{1}^{2}\right) t+z_{1}(t)\right\}
$$

where $z_{1}(t)$ is a Wiener process with variance parameter $\sigma_{1}^{2}$ (Hoel, Port, and Stone 1987, 123). This contrasts with the evolution of the stock price index, which we take to occur in terms of the following process (Rhys and Tippett 1993):

$$
\frac{d P(t)}{P(t)}=\left\{\alpha_{2}+B \log \left[\frac{g(t)}{\mu}\right]\right\} d t+d z_{2}(t)
$$

where $\mu$ is the unconditional mean of the money to stock price ratio and $\alpha_{2}$ is the expected rate of growth (per unit time) (equivalently, the expected infinitesimal buy and hold return) on the stock price index when the money to stock price ratio is in equilibrium, (that is, when $g(t)=\mu$ ). Moreover, the parameter $B$ reflects the higher future expected stock returns when stock prices are currently depressed (that is, when $g(t)>\mu)$ and the lower future expected stock returns implied by a previously thriving stock market (that is, when $g(t)<\mu$ ). Finally, $d z_{2}(t)$ is a white noise process with variance parameter $\sigma_{2}^{2}$. These assumptions will mean that $\left[\frac{d P(t)}{P(t)}\right]^{2}=$ $\sigma_{2}^{2} d t$ is the variance of the rate of growth in stock prices whilst $\frac{d M(t)}{M(t)} \frac{d P(t)}{P(t)}=d z_{1}(t) \cdot d z_{2}(t)=\rho_{12} \sigma_{1} \sigma_{2} d t$ is the covariance between the rate of growth in the money supply and the rate of growth in stock prices (Hoel, Port, and Stone 1987, 142). Here, $\rho_{12}$ is the infinitesimal correlation between the rate of growth in the money supply and the rate of growth in stock prices. ${ }^{7}$

Now, one can substitute equation (7) and equation (9) into equation (6) and thereby show that infinitesimal proportionate increments in the money to stock price ratio will evolve in terms of the following differential equation:

$$
\frac{d g(t)}{g(t)}=\left\{A-B \log \left[\frac{g(t)}{\mu}\right]\right\} d t+d z(t)
$$

where $A=\left(\alpha_{1}-\alpha_{2}+\sigma_{2}^{2}-\rho_{12} \sigma_{1} \sigma_{2}\right)$ and $d z(t)=d z_{1}(t)-d z_{2}(t)$. This in turn will mean $d z(t)$ is a white noise process with variance parameter:

$$
\sigma^{2}=\left(\sigma_{1}^{2}+\sigma_{2}^{2}-2 \rho_{12} \sigma_{1} \sigma_{2}\right)
$$

Moreover, one can obtain the unique (that is, strong) solution of the differential equation (10) by considering the transforming variable:

$$
x(t)=\frac{\sqrt{2 B}}{\sigma} \log \left[\frac{g(t)}{\mu}\right]+\frac{\sigma}{\sqrt{2 B}}-\frac{2 A}{\sigma \sqrt{2 B}}
$$

It then follows $\frac{\partial x}{\partial g}=\frac{\sqrt{2 B}}{\sigma} \frac{1}{g}$ and $\frac{\partial^{2} x}{\partial g^{2}}=-\frac{\sqrt{2 B}}{\sigma} \frac{1}{g^{2}}$ and one can use Itô's formula in conjunction with equation (10) to thereby show:

$$
d x(t)=\frac{\partial x}{\partial g} d g+\frac{\partial^{2} x}{\partial g^{2}}(d g)^{2}=\frac{\sqrt{2 B}}{\sigma}\left[\left\{A-B \log \left[\frac{g(t)}{\mu}\right]\right\} d t+d z(t)\right]-\frac{1}{2} \sigma \sqrt{2 B} d t
$$


Moreover, from equation (12) we also have $\log \left[\frac{g(t)}{\mu}\right]=\frac{A}{B}-\frac{\sigma^{2}}{2 B}+\frac{\sigma}{\sqrt{2 B}} x(t)$ so that substitution into equation (13) implies:

$$
d x(t)=\frac{\sqrt{2 B}}{\sigma}\left[\left\{A-B\left(\frac{A}{B}-\frac{\sigma^{2}}{2 B}+\frac{\sigma}{\sqrt{2 B}} x(t)\right)\right\} d t+d z(t)\right]-\frac{1}{2} \sigma \sqrt{2 B} d t
$$

or equivalently:

$$
d x(t)=-B x(t) d t+\frac{\sqrt{2 B}}{\sigma} d z(t)
$$

Thus, if one multiplies through the above equation by $e^{B t}$ and then collects terms we have:

$$
\frac{d}{d t}\left[e^{B t} x(t)\right]=e^{B t} \frac{\sqrt{2 B}}{\sigma} \frac{d z(t)}{d t}
$$

or upon integrating:

$$
x(t)=x(0) e^{-B t}+\frac{\sqrt{2 B}}{\sigma} \int_{0}^{t} e^{-B(t-s)} d z(s)
$$

This result identifies $x(t)$ as evolving in terms of an Uhlenbeck and Ornstein (1930) process - one of the most widely applied stochastic processes in financial economics (Gibson and Schwartz 1990; Barndorff-Nielsen and Shephard 2001; Hong and Satchell 2012). More important, however, is that substituting equation (12) into equation (15) allows one to show that the unique (that is, strong) solution of the differential equation (10) is given by:

$$
\frac{\sqrt{2 B}}{\sigma} \log \left[\frac{g(t)}{\mu}\right]+\frac{\sigma}{\sqrt{2 B}}-\frac{2 A}{\sigma \sqrt{2 B}}=\left\{\frac{\sqrt{2 B}}{\sigma} \log \left[\frac{g(0)}{\mu}\right]+\frac{\sigma}{\sqrt{2 B}}-\frac{2 A}{\sigma \sqrt{2 B}}\right\} e^{-B t}+\frac{\sqrt{2 B}}{\sigma} \int_{0}^{t} e^{-B(t-s)} d z(s)
$$

or equivalently:

$$
g(t)=\frac{M(t)}{P(t)}=\mu\left[\frac{g(0)}{\mu}\right]^{-B t} \exp \left\{\left(1-e^{-B t}\right)\left[\frac{2 A-\sigma^{2}}{2 B}\right]+\int_{0}^{t} e^{-B(t-s)} d z(s)\right\}
$$

This result summarises the temporal evolution of the money to stock price ratio and will be used as the basis of much of our subsequently summarised empirical analysis. Furthermore, by substituting equation (8) into equation (16), it follows that the stock price index will evolve in terms of the following expression:

$$
\frac{P(t)}{P(0)}=\frac{\frac{g(0)}{\mu} \exp \left\{\left(\alpha_{1}-\frac{1}{2} \sigma_{1}^{2}\right) t+z_{1}(t)\right\}}{\left[\frac{g(0)}{\mu}\right]^{e^{-B t}} \exp \left\{\left(1-e^{-B t}\right)\left[\frac{2 A-\sigma^{2}}{2 B}\right]+\int_{0}^{t} e^{-B(t-s)} d z(s)\right\}}
$$

Moreover, from equation (10) and equation (11) we have:

$$
\frac{2 A-\sigma^{2}}{2 B}=\frac{2\left(\alpha_{1}-\alpha_{2}+\sigma_{2}^{2}-\rho_{12} \sigma_{1} \sigma_{2}\right)-\left(\sigma_{1}^{2}+\sigma_{2}^{2}-2 \rho_{12} \sigma_{1} \sigma_{2}\right)}{2 B}=\frac{\left(2 \alpha_{1}-\sigma_{1}^{2}\right)-\left(2 \alpha_{2}-\sigma_{2}^{2}\right)}{2 B}
$$

and $d z(t)=d z_{1}(t)-d z_{2}(t)$. Substituting these results into the above expression will then show that the unique solution of the differential equation (9) and therefore, the value of the stock price index, will be:

$$
\begin{aligned}
P(t)= & P(0)\left[\frac{g(0)}{\mu}\right]^{1-e^{-B t}} \exp \left\{-\left(1-e^{-B t}\right)\left[\frac{\left(2 \alpha_{1}-\sigma_{1}^{2}\right)-\left(2 \alpha_{2}-\sigma_{2}^{2}\right)}{2 B}\right]\right. \\
& \left.+\left(\alpha_{1}-\frac{1}{2} \sigma_{1}^{2}\right) t+\int_{0}^{t}\left(1-e^{-B(t-s)}\right) d z_{1}(s)+\int_{0}^{t} e^{-B(t-s)} d z_{2}(s)\right\}
\end{aligned}
$$


or equivalently:

$$
\begin{aligned}
P(t)= & P(0) \exp \left\{\left(1-e^{-B t}\right)\left[\log \left(\frac{g(0)}{\mu}\right)-\frac{\left(2 \alpha_{1}-\sigma_{1}^{2}\right)-\left(2 \alpha_{2}-\sigma_{2}^{2}\right)}{2 B}\right]\right. \\
& \left.+\left(\alpha_{1}-\frac{1}{2} \sigma_{1}^{2}\right) t+\int_{0}^{t}\left(1-e^{-B(t-s)}\right) d z_{1}(s)+\int_{0}^{t} e^{-B(t-s)} d z_{2}(s)\right\}
\end{aligned}
$$

One can then take logarithms across the above expression and apply the expectation operator to thereby show that the logarithmic return on the stock price index will be normally distributed with the mean: ${ }^{8}$

$$
E\left\{\log \left[\frac{P(t)}{P(0)}\right]\right\}=\left(1-e^{-B t}\right)\left[\log \left(\frac{g(0)}{\mu}\right)-\frac{\left(2 \alpha_{1}-\sigma_{1}^{2}\right)-\left(2 \alpha_{2}-\sigma_{2}^{2}\right)}{2 B}\right]+\left(\alpha_{1}-\frac{1}{2} \sigma_{1}^{2}\right) t
$$

A similar application of the expectation operator will show that the variance of the logarithmic return on the stock price index will amount to:

$$
\begin{aligned}
\operatorname{Var}\left\{\log \left[\frac{P(t)}{P(0)}\right]\right\}= & \operatorname{Var}\left\{\int_{0}^{t}\left(1-e^{-B(t-s)}\right) d z_{1}(s)\right\}+\operatorname{Var}\left\{\int_{0}^{t} e^{-B(t-s)} d z_{2}(s)\right\} \\
& +2 \operatorname{Cov}\left\{\int_{0}^{t}\left(1-e^{-B(t-s)}\right) d z_{1}(s), \int_{0}^{t} e^{-B(t-s)} d z_{2}(s)\right\}
\end{aligned}
$$

Moreover, one can evaluate each term on the right-hand side of the above expression and thereby show:

$$
\begin{gathered}
\operatorname{Var}\left\{\int_{0}^{t}\left(1-e^{-B(t-s)}\right) d z_{1}(s)\right\}=\sigma_{1}^{2} \int_{0}^{t}\left(1-e^{-B(t-s)}\right)^{2} d s \\
=\sigma_{1}^{2} t-\frac{2 \sigma_{1}^{2}}{B}\left(1-e^{-B t}\right)+\frac{\sigma_{1}^{2}}{2 B}\left(1-e^{-2 B t}\right)
\end{gathered}
$$

and:

$$
\operatorname{Var}\left\{\int_{0}^{t} e^{-B(t-s)} d z_{2}(s)\right\}=\sigma_{2}^{2} \int_{0}^{t} e^{-2 B(t-s)} d s=\frac{\sigma_{2}^{2}}{2 B}\left(1-e^{-2 B t}\right)
$$

Finally, one can determine the covariance term, namely:

$$
\begin{gathered}
\operatorname{Cov}\left\{\int_{0}^{t}\left(1-e^{-B(t-s)}\right) d z_{1}(s), \int_{0}^{t} e^{-B(t-s)} d z_{2}(s)\right\}=\rho_{12} \sigma_{1} \sigma_{2} \int_{0}^{t}\left(e^{-B(t-s)}-e^{-2 B(t-s)}\right) d s \\
=\frac{\rho_{12} \sigma_{1} \sigma_{2}}{B}\left(1-e^{-B t}\right)-\frac{\rho_{12} \sigma_{1} \sigma_{2}}{2 B}\left(1-e^{-2 B t}\right)
\end{gathered}
$$

Bringing these results together will then show:

$$
\operatorname{Var}\left\{\log \left[\frac{P(t)}{P(0)}\right]\right\}=\sigma_{1}^{2} t-\frac{2 \sigma_{1}^{2}-2 \rho_{12} \sigma_{1} \sigma_{2}}{B}\left(1-e^{-B t}\right)+\frac{\sigma_{1}^{2}+\sigma_{2}^{2}-2 \rho_{12} \sigma_{1} \sigma_{2}}{2 B}\left(1-e^{-2 B t}\right)
$$

is the variance of the logarithmic return on the stock price index. ${ }^{9}$ 


\section{Data and analysis}

To demonstrate the application of these results, we collected annual data $(t=1)$ on the U.S. M2 monetary aggregate and the S\&P Composite Index for the United States covering the period from 1871 until $2018 .{ }^{10}$ The M2 monetary aggregate for each year is then divided by the value of the S\&P Composite Index for that year to determine the money to stock price ratio, $g(t)$, for each of the given years. Here, one can take logarithms across equation (16) and thereby establish the canonical form of the regression equation applied in our empirical analysis; namely:

$$
\log \left[\frac{g(t)}{g(0)}\right]=\left(1-e^{-B t}\right)\left\{\left[\frac{2 A-\sigma^{2}}{2 B}+\log (\mu)\right]-\log [g(0)]\right\}+\int_{0}^{t} e^{-B(t-s)} d z(s)
$$

Note how this equation implies that the conditional mean of the logarithmic variation in the money to stock price ratio will be:

$$
E\left\{\log \left[\frac{g(t)}{g(0)}\right]\right\}=\left(1-e^{-B t}\right)\left\{\left[\frac{2 A-\sigma^{2}}{2 B}+\log (\mu)\right]-\log [g(0)]\right\}
$$

Now, here it will be recalled from equation (10) and equation (11) that $d z(t)$ is a white noise process with variance parameter $\sigma^{2}=\left(\sigma_{1}^{2}+\sigma_{2}^{2}-2 \rho_{12} \sigma_{1} \sigma_{2}\right)$. It follows from this that the variance of the logarithmic variation in the money to stock price ratio will be: ${ }^{11}$

$$
\operatorname{Var}\left\{\log \left[\frac{g(t)}{g(0)}\right]\right\}=\operatorname{Var}\left\{\int_{0}^{t} e^{-B(t-s)} d z(s)\right\}=e^{-2 B t} \frac{\sigma^{2}}{2 B} \int_{0}^{t} e^{2 B s} d s=\frac{\sigma^{2}}{2 B}\left(1-e^{-2 B t}\right)
$$

or equivalently:

$$
\operatorname{Var}\left\{\log \left[\frac{g(t)}{g(0)}\right]\right\}=\frac{\left(\sigma_{1}^{2}+\sigma_{2}^{2}-2 \rho_{12} \sigma_{1} \sigma_{2}\right)}{2 B}\left(1-e^{-2 B t}\right)
$$

These results characterise the logarithm of the money to stock price ratio as evolving in terms of an elastic or mean reverting random walk with a long-run mean of:

$$
\frac{2 A-\sigma^{2}}{2 B}+\log (\mu)=\frac{\left(2 \alpha_{1}-\sigma_{1}^{2}\right)-\left(2 \alpha_{2}-\sigma_{2}^{2}\right)}{2 B}+\log (\mu)
$$

and an expected restoring force which is proportional to the difference between the long-run mean and the logarithm of the current instantaneous money to stock price ratio, $\log [g(0)]$. The constant of proportionality or 'speed of adjustment coefficient' is given by $0 \leq\left(1-e^{-B t}\right) \leq 1$. $^{12}$

We implemented equation (18) by regressing the logarithmic variation in the money to stock price ratio over each year against the logarithm of the money to stock price ratio at the beginning of the year (that is, at the end of the previous year). Here, Figure 1 summarises the evolution of the annual logarithmic variation in the money to stock price ratio over the period from 1871 to 2018 covered by our sample. Moreover, Table 1 summarises the sample size, parameter estimates, and their associated $t$-scores as obtained from this canonical form of our regression model. The results summarised in this table show that the estimated constant in the regression equation is:

$$
\left(1-e^{-B}\right)\left[\frac{2 A-\sigma^{2}}{2 B}+\log (\mu)\right]=0.0636
$$

with an associated $t$-score of 2.5553 , which differs from zero at better than the $1 \%$ level of significance. Note also how the estimated speed of adjustment coefficient amounts to $\left(1-e^{-B}\right)=0.0343$ with an associated $t$-score of -2.2770 , which again, is different from zero but on this occasion at better than the $2.5 \%$ level of significance. ${ }^{13}$ Moreover, a speed of adjustment coefficient of this magnitude implies that the estimated 'half-life' of the period it takes for the money to stock price ratio to converge towards its long-run mean amounts to $\frac{\log (2)}{0.0343}=20.2228$ or 


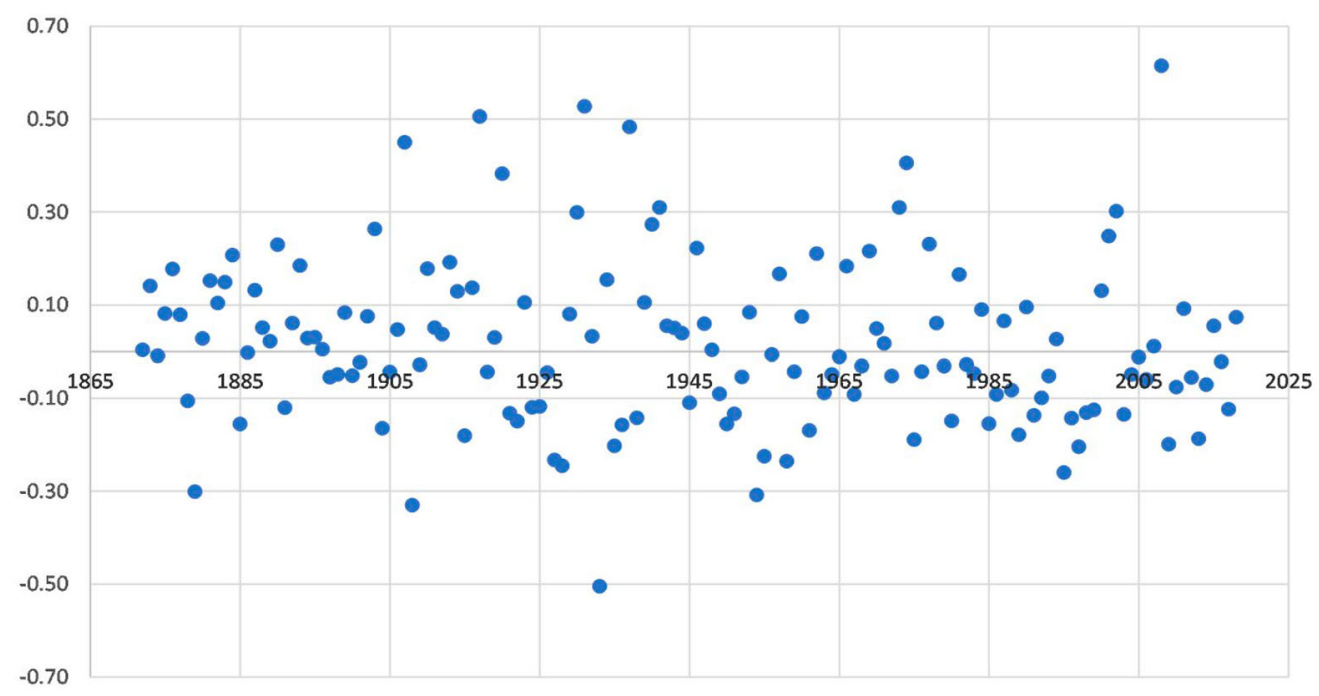

Figure 1. Annual Logarithmic Variation of the ratio of the M2 monetary aggregate to the S\&P Composite Stock Price Index for the U.S. economy covering the years from 1871 until 2018.

Notes: This figure summarises the evolution of the annual logarithmic variation, $\log \left[\frac{g(t+1)}{g(t)}\right]$, in the money to stock price ratio, $g(t)$, over the period from $t=1871$ to $t=2017$ covered by our sample.

approximately, 20 years. Thus, our parameter estimates are compatible with a slowly converging elastic random walk under which the logarithm of the money to stock price ratio converges towards a long-run mean of:

$$
\frac{2 A-\sigma^{2}}{2 B}+\log (\mu)=\frac{0.0636}{0.0343}=1.8542
$$

This in turn implies that the money to stock price ratio itself converges towards a long-run mean of $e^{1.8542}=6.3978$. Moreover, the estimate for the speed of adjustment coefficient implies that the parameter $B=-\log (1-0.0343)=0.0349$. Finally, it will be recalled that the Durbin-Watson statistic has an expected value of $E(d) \approx 2$ under the null hypothesis that the error term, $\int_{0}^{t} e^{-B(t-s)} d z(s)$, in equation (18) is serially independent (Greene 2019, 1041). Since, from Table 1, the observed value of the Durbin-Watson statistic - namely, $d=1.9798$ - is not statistically different from $E(d) \approx 2$ at all conventional levels of statistical significance, one may conclude that there is no evidence of an autocorrelated error term in our regression analysis. ${ }^{14}$

\section{Unanticipated inflation}

As previously noted, Friedman $(1977,456)$ amongst others argue that the inflationary implications of unexpected variations in monetary policy will, in general, have a disruptive impact on the output and investment decisions implemented by firms. This arises from the fact that 'commitments entered into' by firms 'depend not only on current observable prices, but also on the prices expected to prevail throughout the term of the commitment'. Thus, when the inflationary expectations on which the output and investment decisions implemented by firms turn out to be incorrect, firm values will fall and the money to stock price ratio will rise. ${ }^{15}$ One can demonstrate the impact of unexpected variations in monetary policy by modelling prices and inflation in terms of the Consumer Price Index (CPI) for the United States. ${ }^{16}$ Thus, if one defines $I(t)$ to be the price level at time $t$ using the CPI, it then follows that the (continuously compounded) rate of inflation over the period from time zero to time $t$ may be represented as:

$$
\log \left[\frac{I(t)}{I(0)}\right]=\theta t+\int_{0}^{t} d \eta(s)=\theta t+\eta(t)
$$


Table 1. Parameter estimates for the money to stock price ratio using the annual $N=147$ U.S. data points covering the period from 1871 until 2018.

\begin{tabular}{lcr}
\hline & Parameter & $t$-score \\
\hline$\left(1-e^{-B}\right)\left[\frac{2 A-\sigma^{2}}{2 B}+\log (\mu)\right]$ & 0.0636 & 2.5553 \\
$\left(1-e^{-B}\right)$ & 0.0343 & -2.2770 \\
Adjusted $R^{2}$ & 0.0279 & \\
Durbin-Watson Statistic & 1.9798 & \\
\hline
\end{tabular}

Notes: Columns one and two summarise parameter estimates and their associated $t$-scores for the canonical regression equation (18). Several 'robustness' tests were applied to assess the integrity of the results summarised in this table. First, we applied a 95\% winsorisation to our data and then re-estimated the regression relationship. Parameter estimates and their associated $t$ scores under this procedure were almost identical to those summarised above. Second, we augmented the regression equation by adding a dummy variable to capture any discriminating effects arising out of the Global Financial Crisis (GFC). The dummy variable takes a unit value for the years 2008, 2009 and 2010 and a value of zero in other years. The $t$ score associated with the regression coefficient for the dummy variable does not differ from zero at all generally accepted levels of statistical significance. Moreover, the parameter estimates for $\left(1-e^{-B}\right)\left[\frac{2 A-\sigma^{2}}{2 B}+\log (\mu)\right]$ and $\left(1-e^{-B}\right)$ as well as their associated $t$ scores under the dummy variable augmented regression model are virtually identical to those summarised above. Finally, we eliminated all data relating to the years of the GFC (that is, for the years 2008, 2009 and 2010) and then re-estimated all parameters of the regression equation (18). The parameter estimates and their associated $t$ scores are again virtually identical to those summarised above.

where $\theta$ is the expected rate of inflation (per unit time) and $d \eta(t)$ is a white noise process with variance parameter, $\delta^{2}$. This in turn will mean that the inflation rate evolves in terms of the Gaussian probability density with a mean of $E\left\{\log \left[\frac{I(t)}{I(0)}\right]\right\}=\theta t$ and variance of $\operatorname{Var}\left\{\log \left[\frac{I(t)}{I(0)}\right]\right\}=\delta^{2} t$ (Hoel, Port, and Stone 1987, 122-124). Moreover, the cross covariance between logarithmic variations in the money to stock price ratio and the rate of inflation will be:

$$
\operatorname{Cov}\left\{\log \left[\frac{g(t)}{g(0)}\right], \log \left[\frac{I(t)}{I(0)}\right]\right\}=\operatorname{Cov}\left\{\int_{0}^{t} e^{-B(t-s)} d z(s), \int_{0}^{t} d \eta(s)\right\}
$$

or upon evaluation:

$$
\operatorname{Cov}\left\{\int_{0}^{t} e^{-B(t-s)} d z(s), \int_{0}^{t} d \eta(s)\right\}=\rho \sigma \delta e^{-B t} \int_{0}^{t} e^{B s} d s=\frac{\rho \sigma \delta}{B}\left(1-e^{-B t}\right)
$$

where $\rho$ is the infinitesimal correlation coefficient between the white noise process, $d z(t)$, in equation (18) and the white noise process, $d \eta(t)$, in equation (21). Moreover, one can use the above result in conjunction with equation (20a) and the variance for the rate of inflation given above to determine the cross correlation between logarithmic variations in the money to stock price ratio and the inflation rate as follows: ${ }^{17}$

$$
\frac{\operatorname{Cov}\left\{\log \left[\frac{g(t)}{g(0)}\right], \log \left[\frac{I(t)}{I(0)}\right]\right\}}{\sqrt{\operatorname{Var}\left\{\log \left[\frac{g(t)}{g(0)}\right]\right\}} \sqrt{\operatorname{Var}\left\{\log \left[\frac{I(t)}{I(0)}\right]\right\}}}=\frac{\frac{\rho \sigma \delta}{B}\left(1-e^{-B t}\right)}{\sqrt{\frac{\sigma^{2}}{2 B}\left(1-e^{-2 B t}\right)} \sqrt{\delta^{2} t}}=\rho \sqrt{\frac{2\left(1-e^{-B t}\right)}{B t\left(1+e^{-B t}\right)}}
$$

This in turn will mean that under the assumption that the logarithm of the money to stock price ratio and the logarithmic rate of inflation are jointly Gaussian, one can augment equation (18) for the effect of unexpected 
inflation on the money to stock price ratio by using the following regression equation (Freeman, 151-152):

$$
\begin{gathered}
\log \left[\frac{g(t)}{g(0)}\right]=\left(1-e^{-B t}\right)\left\{\left[\frac{2 A-\sigma^{2}}{2 B}+\log (\mu)\right]-\log [g(0)]\right\}+\frac{\rho \sigma}{B \delta} \frac{\left(1-e^{-B t}\right)}{t}\left\{\log \left[\frac{I(t)}{I(0)}\right]-\theta t\right\} \\
+\sqrt{1-\frac{2 \rho^{2}\left(1-e^{-B t}\right)}{B t\left(1+e^{-B t}\right)}} \int_{0}^{t} e^{-B(t-s)} d z(s)
\end{gathered}
$$

It then follows that logarithmic variations in the money to stock price ratio will evolve in terms of the Gaussian probability density with a mean of:

$$
E\left\{\log \left[\frac{g(t)}{g(0)}\right]\right\}=\left(1-e^{-B t}\right)\left\{\left[\frac{2 A-\sigma^{2}}{2 B}+\log (\mu)-\frac{\rho \sigma \theta}{B \delta}\right]-\log [g(0)]+\frac{\rho \sigma}{B \delta t} \log \left[\frac{I(t)}{I(0)}\right]\right\}
$$

Moreover, the variance of logarithmic variations in the money to stock price ratio amounts to:

$$
\operatorname{Var}\left\{\log \left[\frac{g(t)}{g(0)}\right]\right\}=\frac{\sigma^{2}}{2 B}\left\{1-\frac{2 \rho^{2}\left(1-e^{-B t}\right)}{B t\left(1+e^{-B t}\right)}\right\}\left(1-e^{-2 B t}\right)
$$

These results characterise the evolution of the logarithm of the money to stock price ratio in terms of an elastic or mean reverting random walk with a long-run mean of:

$$
\left[\frac{2 A-\sigma^{2}}{2 B}+\log (\mu)\right]-\frac{\rho \sigma \theta}{B \delta}=\frac{\left(2 \alpha_{1}-\sigma_{1}^{2}\right)-\left(2 \alpha_{2}-\sigma_{2}^{2}\right)}{2 B}+\log (\mu)-\frac{\rho \sigma \theta}{B \delta}
$$

and an expected restoring force which is proportional to the difference between the long-run mean and the logarithm of the current instantaneous money to stock price ratio, $\log [g(0)]$. The constant of proportionality or 'speed of adjustment coefficient' is given by $0 \leq\left(1-e^{-B t}\right) \leq 1$.

One can illustrate the application of this result by using the previously applied annual $(t=1)$ money to stock price ratio data for the US economy covering the period from 1871 until 2018 in conjunction with the annual CPI inflation rate data covering the same period. Here, Figure 2 summarises the annual rates of consumer price index inflation and M2 monetary growth for the U.S. economy covering this period. It is evident from Figure 2 that there are several periods of high monetary growth with consequential high rates of annual inflation over the near century and a half covered by our data. Moreover, Table 2 summarises the sample size, parameter estimates, and their associated $t$-scores as obtained from the augmented regression equation (24). Note how the inclusion of the inflation rate variable in the regression equation (24) returns an estimated regression constant of:

$$
\left(1-e^{-B}\right)\left\{\left[\frac{2 A-\sigma^{2}}{2 B}+\log (\mu)\right]-\frac{\rho \sigma \theta}{B \delta}\right\}=0.0742
$$

with an associated $t$-score of 2.9850. A $t$-score of this magnitude is statistically different from zero at all conventional levels of statistical significance. Moreover, the estimated speed of adjustment coefficient amounts to $\left(1-e^{-B}\right)=0.0544$ with an associated $t$-score of -3.3896 , which again, is different from zero at all conventional levels of statistical significance. A speed of adjustment coefficient of this magnitude implies an estimated 'half-life' of the adjustment period of $\frac{\log (2)}{0.0544}=12.7355$ or approximately 13 years. Whilst this is a little lower than our estimate of the half-life based on the money to stock price ratio for the canonical form of the regression equation (18) (which is roughly 20 years), our parameter estimates are still compatible with the hypothesis that the money to stock price ratio evolves in terms of a slowly converging elastic random walk under which the logarithm of the money to stock price ratio converges towards a long-run mean of:

$$
\left[\frac{2 A-\sigma^{2}}{2 B}+\log (\mu)\right]-\frac{\rho \sigma \theta}{B \delta}=\frac{0.0742}{0.0544}=1.3634
$$

Note that the above long-run mean is slightly lower than the long-run mean of 1.8542 obtained from the regression equation (18) and which makes no allowance for the effects of inflation. And, this in turn implies that the money to stock price ratio itself converges towards a long-run mean of $e^{1.3634}=3.9095$. 


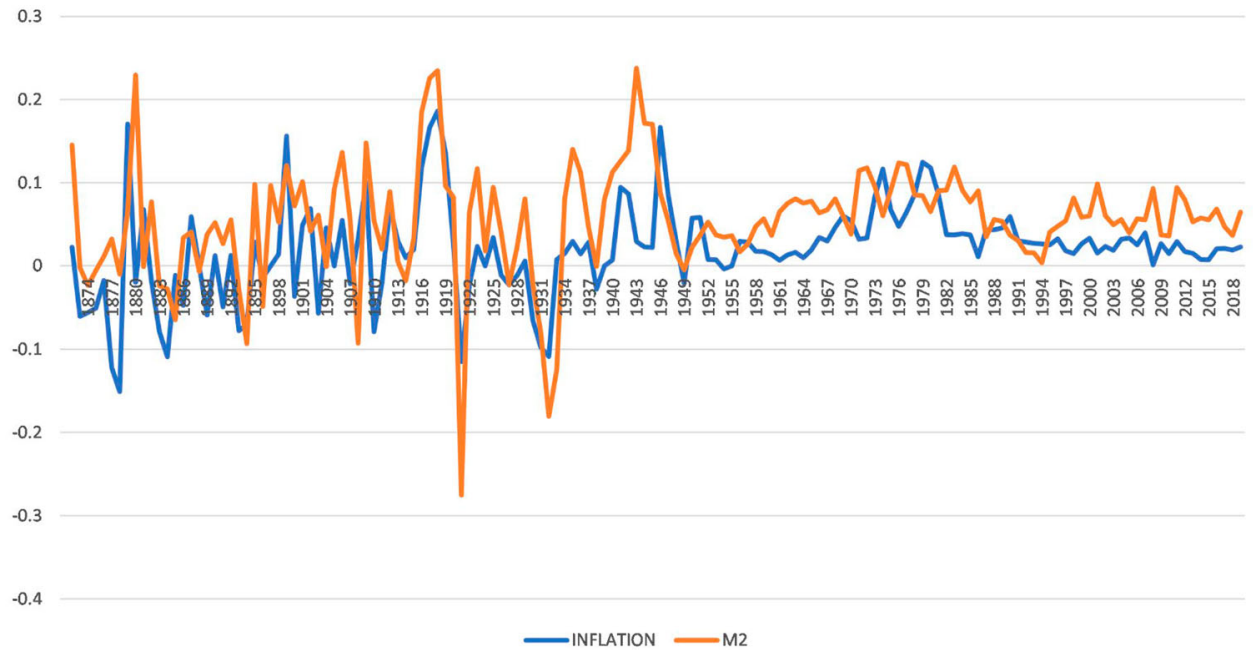

Figure 2. Annual rates of consumer price index inflation and M2 monetary growth for the U.S. economy covering the years from 1871 until 2018. Notes: The annual inflation series is $\log \left[\frac{l(t+1)}{I(t)}\right]$, where $I(t)$ is the Consumer Price Index for the United States for the period from $t=1871$ to $t=2018$ covered by our sample. The $M 2$ series is $\log \left[\frac{M(t+1)}{M(t)}\right]$, where $M(t)$ is the $M 2$ monetary aggregate for the United States.

Table 2. Parameter estimates for the money to stock price ratio using the annual $N=$ 147 U.S. data points covering the period from 1871 until 2018.

\begin{tabular}{lcr}
\hline & Parameter & $t$-score \\
\hline$\left(1-e^{-B}\right)\left\{\left[\frac{2 A-\sigma^{2}}{2 B}+\log (\mu)\right]-\frac{\rho \sigma \theta}{B \delta}\right\}$ & 0.0742 & 2.9850 \\
$\left(1-e^{-B}\right)$ & 0.0544 & -3.3896 \\
$\frac{\rho \sigma}{B \delta}\left(1-e^{-B}\right)$ & 0.8562 & 3.1380 \\
Adjusted $R^{2}$ & 0.0857 & \\
Durbin-Watson Statistic & 2.0141 & \\
\hline
\end{tabular}

Notes: Columns one and two summarise parameter estimates and their associated $t$ scores for the inflation augmented regression equation (24). Several 'robustness' tests were applied to assess the integrity of the results summarised in this table. First, we applied a $95 \%$ winsorisation to our data and then re-estimated the regression relationship. Parameter estimates and their associated $t$ scores under this procedure were almost identical to those summarised above. Second, we augmented the regression equation by adding a dummy variable to capture any discriminating effects arising out of the Global Financial Crisis (GFC). The dummy variable takes a unit value for the years 2008, 2009 and 2010 and a value of zero in other years. The $t$ score associated with the regression coefficient for the dummy variable does not differ from zero at all generally accepted levels of statistical significance. Moreover, the parameter estimates for $\left(1-e^{-B}\right)\left\{\left[\frac{2 A-\sigma^{2}}{2 B}+\log (\mu)\right]-\frac{\rho \sigma \theta}{B \delta}\right\},\left(1-e^{-B}\right)$ and $\frac{\rho \sigma}{B \delta}\left(1-e^{-B}\right)$ as well as their associated $t$ scores under the dummy variable augmented regression model, are virtually identical to those summarised above. Finally, we eliminated all data relating to the years of the GFC (that is, for the years 2008, 2009 and 2010) and then re-estimated all parameters of the regression equation (24). The parameter estimates and their associated $t$ scores are again virtually identical to those summarised above.

Note also how the estimated sensitivity coefficient associated with the inflation rate variable is $\frac{\rho \sigma}{B \delta}\left(1-e^{-B}\right)=$ 0.8562 with an associated the $t$-score of 3.1380 . This $t$-score is again statistically different from zero at all conventional levels of statistical significance. ${ }^{18}$ This in turn implies that the money to stock price ratio increases as the 
inflation rate increases (equivalently, the stock price index falls relative to the M2 monetary aggregate). Moreover, the estimate for the speed of adjustment coefficient implies that the parameter $B=-\log (1-0.0544)=$ 0.0600 . Finally, since the observed value of the Durbin-Watson statistic - namely, $d=2.0141$ - is statistically equivalent to its expected value of $E(d) \approx 2$ at all conventional levels of statistical significance, one may conclude that there is no evidence of an autocorrelated error term in our regression analysis (Greene 2019, 1041). ${ }^{19}$

The overall conclusion from the analysis of the estimated joint probability density considered here is that the money to stock price ratio slowly converges towards a long-run mean of around $e^{1.3634}=3.9095$. Moreover, the speed of adjustment coefficient amounts to 0.0544 and implies a half-life for the adjustment period of 12.7355 years. These parameter estimates contrast with those of the estimated marginal probability density developed in the previous section, for which the money to stock price ratio converges towards a long-run mean of around $e^{1.8542}=6.3978$ with a speed of adjustment coefficient of 0.0343 and a half-life for the adjustment period of 20.2228 years. The important point to take from this analysis, however, is that the half-life measures for both the joint and the marginal probability densities imply that the money to stock price ratio evolves in terms of a very slowly converging mean reversion process.

\section{Optimal consumption-investment rules}

We have previously observed how unexpected monetary disturbances induce disequilibria in asset markets by driving a wedge between actual and desired monetary holdings. Economic agents respond by rebalancing their asset portfolios and this in turn disseminates the effects of unexpected changes in monetary policy into other markets. Until now, however, our principal concern has been with the inflationary implications of unexpected variations in monetary policy and the disruptive impact they have on the production and investment decisions implemented by firms and by implication, the money to stock price ratio. We now present a more general approach to the re-balancing issues associated with unexpected monetary disturbances by considering an economic agent whose income is generated by the returns from an investment portfolio comprised of the stock price index and the holding of money.

We thus suppose the economic agent allocates a proportion, $\gamma(t)$, of their wealth to an investment in the stock index whose price evolves in terms of equation (9), with the complementary proportionate balance, $(1-\gamma(t))$, being held in money. Since the M2 monetary aggregate on which our previously summarised empirical analysis is based includes savings and time deposits that encompass the payment of interest, we let $r$ be the return (per unit time) on monetary holdings (Lim and Sriram 2003, 10). It then follows that the infinitesimal increment in the economic agent's wealth will be:

$$
d W(t)=\left\{r d t+\gamma(t)\left[\left(\alpha_{2}-r\right) d t+B \log \left[\frac{g(t)}{\mu}\right] d t+d z_{2}(t)\right]\right\} W(t)-C(t) d t
$$

where $C(t)$ is the economic agent's consumption expenditure measured on a per unit time basis. Applying the expectation operator across the above equation will then show that the expected infinitesimal increment in wealth will be:

$$
E[d W(t)]=\left\{r+\gamma(t)\left[\left(\alpha_{2}-r\right)+B \log \left[\frac{g(t)}{\mu}\right]\right]\right\} W(t) d t-C(t) d t
$$

Similarly, the variance of the infinitesimal increment in wealth is given by:

$$
\operatorname{Var}[d W(t)]=\gamma^{2}(t) W^{2}(t) \sigma_{2}^{2} d t
$$

Moreover, one can use the wealth constraint defined by equation (27) in conjunction with equation (10) describing the evolution of the money to stock price ratio and thereby show that the covariance between infinitesimal proportionate variations in the economic agent's wealth and infinitesimal proportionate variations in the money 
to stock price ratio is:

$$
\frac{d W(t)}{W(t)} \frac{d g(t)}{g(t)}=\gamma(t) d z_{2}(t)\left(d z_{1}(t)-d z_{2}(t)\right)=\gamma(t)\left(\rho_{12} \sigma_{1} \sigma_{2}-\sigma_{2}^{2}\right) d t
$$

and where from equation (7) and equation (9), $\rho_{12}$ is the infinitesimal correlation between the rate of growth in the money supply and the rate of growth in the stock price index.

Now, the economic agent's objective is to maximise the expected discounted utility of lifetime consumption, or (Merton 1969, 252):

$$
H(W, g, t) \equiv E\left\{\int_{0}^{\infty} e^{-i t} U[C(t)] d t\right\}
$$

where $U[C(t)]$ is the infinitesimal utility associated with consumption at time $t$ and $i$ is the own rate of discount relating to consumption expenditure. One can then combine the objective criterion defined by equation (30) with the differential equation (10) describing the evolution of the money to stock price ratio and the wealth constraint defined by equation (27), to formulate the unoptimised Hamilton-Jacobi-Bellman equation for the optimal control problem implied by our analysis (Arnold 1974, 212-214): ${ }^{20}$

$$
\begin{gathered}
e^{-i t} U(C)+\left[r+\gamma\left\{\left(\alpha_{2}-r\right)+B \log \left(\frac{g}{\mu}\right)\right\}\right] W \frac{\partial H}{\partial W}-C \frac{\partial H}{\partial W}+\left\{A-B \log \left(\frac{g}{\mu}\right)\right\} g \frac{\partial H}{\partial g}+\frac{\partial H}{\partial t} \\
+\frac{1}{2} \gamma^{2} W^{2} \sigma_{2}^{2} \frac{\partial^{2} H}{\partial W^{2}}+\gamma\left(\rho_{12} \sigma_{1} \sigma_{2}-\sigma_{2}^{2}\right) W g \frac{\partial^{2} H}{\partial W \partial g}+\frac{1}{2}\left(\sigma_{1}^{2}+\sigma_{2}^{2}-2 \rho_{12} \sigma_{1} \sigma_{2}\right) g^{2} \frac{\partial^{2} H}{\partial g^{2}}=0
\end{gathered}
$$

Standard optimisation procedures based on the choice variables, $C$ and $\gamma$, will then lead to the following envelope condition:

$$
e^{-i t} U^{\prime}(C)-\frac{\partial H}{\partial W}=0
$$

as well as the stock price index demand equation: ${ }^{21}$

$$
\left\{\left(\alpha_{2}-r\right)+B \log \left(\frac{g}{\mu}\right)\right\} W \frac{\partial H}{\partial W}+\gamma W^{2} \sigma_{2}^{2} \frac{\partial^{2} H}{\partial W^{2}}+\left(\rho_{12} \sigma_{1} \sigma_{2}-\sigma_{2}^{2}\right) W g \frac{\partial^{2} H}{\partial W \partial g}=0
$$

It facilitates subsequent analysis, however, if the stock price index demand equation is stated in the following equivalent form:

$$
\gamma=-\frac{\left\{\left(\alpha_{2}-r\right)+B \log \left(\frac{g}{\mu}\right)\right\} \frac{\partial H}{\partial W}+\left(\rho_{12} \sigma_{1} \sigma_{2}-\sigma_{2}^{2}\right) g \frac{\partial^{2} H}{\partial W \partial g}}{W \sigma_{2}^{2} \frac{\partial^{2} H}{\partial W^{2}}}
$$

Substituting the stock price index demand equation (33) into the unoptimised Hamilton-Jacobi-Bellman equation (31) will show for the indefinite envelope condition (32), that the Hamilton-Jacobi-Bellman equation may be restated as:

$$
\begin{gathered}
e^{-i t} U(C)-C \frac{\partial H}{\partial W}+r W \frac{\partial H}{\partial W}+\left\{A-B \log \left(\frac{g}{\mu}\right)\right\} g \frac{\partial H}{\partial g}+\frac{\partial H}{\partial t}+ \\
\frac{1}{2}\left(\sigma_{1}^{2}+\sigma_{2}^{2}-2 \rho_{12} \sigma_{1} \sigma_{2}\right) g^{2} \frac{\partial^{2} H}{\partial g^{2}}-\frac{1}{2} \frac{\left[\left\{\left(\alpha_{2}-r\right)+B \log \left(\frac{g}{\mu}\right)\right\} \frac{\partial H}{\partial W}+\left(\rho_{12} \sigma_{1} \sigma_{2}-\sigma_{2}^{2}\right) g \frac{\partial^{2} H}{\partial W \partial g}\right]^{2}}{\sigma_{2}^{2} \frac{\partial^{2} H}{\partial W^{2}}}=0
\end{gathered}
$$

Now, if the envelope condition (32) is based on the Bernoulli preference function $U(C)=\log (C)$, it will then follow that $U^{\prime}(C)=\frac{1}{C}$ (Bernoulli 1954). Moreover, the envelope condition (32) will then imply $\frac{1}{C}=e^{i t} \frac{\partial H}{\partial W}$ or 
equivalently:

$$
e^{-i t} U(C)=e^{-i t} \log (C)=-e^{-i t} \log \left(e^{i t} \frac{\partial H}{\partial W}\right)
$$

and $C \frac{\partial H}{\partial W}=e^{-i t}$. One can then bring these results together and thereby show:

$$
e^{-i t} U(C)-C \frac{\partial H}{\partial W}=e^{-i t} \log (C)-C \frac{\partial H}{\partial W}=-e^{-i t} \log \left(e^{i t} \frac{\partial H}{\partial W}\right)-e^{-i t}
$$

Substituting equation (35) into equation (34) will then show for Bernoulli preferences, that the optimised Hamilton-Jacobi-Bellman equation takes the form:

$$
\begin{gathered}
-e^{-i t} \log \left(e^{i t} \frac{\partial H}{\partial W}\right)-e^{-i t}+r W \frac{\partial H}{\partial W}+\left\{A-B \log \left(\frac{g}{\mu}\right)\right\} g \frac{\partial H}{\partial g}+\frac{\partial H}{\partial t}+ \\
\frac{1}{2}\left(\sigma_{1}^{2}+\sigma_{2}^{2}-2 \rho_{12} \sigma_{1} \sigma_{2}\right) g^{2} \frac{\partial^{2} H}{\partial g^{2}}-\frac{1}{2} \frac{\left[\left\{\left(\alpha_{2}-r\right)+B \log \left(\frac{g}{\mu}\right)\right\} \frac{\partial H}{\partial W}+\left(\rho_{12} \sigma_{1} \sigma_{2}-\sigma_{2}^{2}\right) g \frac{\partial^{2} H}{\partial W \partial g}\right]^{2}}{\sigma_{2}^{2} \frac{\partial^{2} H}{\partial W^{2}}}=0
\end{gathered}
$$

Now, Polyanin and Zaitsev $(2012,805)$ demonstrate how it is particularly difficult to determine closed form solutions for 'Bellman type equations' like this. Fortunately, in the present case one can use the method of undetermined coefficients to show how (O’Neil 1987, 113): ${ }^{22}$

$$
H(W, g, t)=e^{-i t}\left\{J+N \log (W)+K \log \left(\frac{g}{\mu}\right)+L\left[\log \left(\frac{g}{\mu}\right)\right]^{2}\right\}
$$

constitutes a particular solution of the Hamilton-Jacobi-Bellman equation (36) provided $N=\frac{1}{i}$, and the constants, $J, K$ and $L$, are defined by the following system of linear equations:

$$
\left\{\begin{array}{l}
\frac{B^{2}}{2 i \sigma_{2}^{2}}-i L-2 L B=0 \\
2 A L-B K-i K-\left(\sigma_{1}^{2}+\sigma_{2}^{2}-2 \rho_{12} \sigma_{1} \sigma_{2}\right) L+\frac{1}{i \sigma_{2}^{2}}\left(\alpha_{2}-r\right) B=0 \\
\log (i)-1+\frac{r}{i}+A K-i J+\frac{1}{2}\left(\sigma_{1}^{2}+\sigma_{2}^{2}-2 \rho_{12} \sigma_{1} \sigma_{2}\right)(2 L-K)+\frac{\left(\alpha_{2}-r\right)^{2}}{2 i \sigma_{2}^{2}}=0
\end{array}\right.
$$

The first of the above equations show:

$$
L=\frac{B^{2}}{2 i \sigma_{2}^{2}(2 B+i)}
$$

Substituting this expression for $L$ into the second of the above equations will also show:

$$
K=\frac{2 A B^{2}-\left(\sigma_{1}^{2}+\sigma_{2}^{2}-2 \rho_{12} \sigma_{1} \sigma_{2}\right) B^{2}}{2 i \sigma_{2}^{2}(2 B+i)(B+i)}+\frac{\left(\alpha_{2}-r\right) B}{i \sigma_{2}^{2}(B+i)}
$$

Finally, one can substitute the expressions for $K$ and $L$ into the third equation in which case we have:

$$
J=\frac{\log (i)}{i}-\frac{1}{i}+\frac{r}{i^{2}}+\frac{2 A^{2} B^{2}-\left(\sigma_{1}^{2}+\sigma_{2}^{2}-2 \rho_{12} \sigma_{1} \sigma_{2}\right) A B^{2}}{2 i^{2} \sigma_{2}^{2}(2 B+i)(B+i)}+\frac{\left(\alpha_{2}-r\right) A B}{i^{2} \sigma_{2}^{2}(B+i)}+\frac{\left(\alpha_{2}-r\right)^{2}}{2 i^{2} \sigma_{2}^{2}}
$$




$$
+\frac{1}{2}\left(\sigma_{1}^{2}+\sigma_{2}^{2}-2 \rho_{12} \sigma_{1} \sigma_{2}\right)\left\{\frac{B^{2}}{i^{2} \sigma_{2}^{2}(2 B+i)}-\frac{2 A B^{2}-\left(\sigma_{1}^{2}+\sigma_{2}^{2}-2 \rho_{12} \sigma_{1} \sigma_{2}\right) B^{2}}{2 i^{2} \sigma_{2}^{2}(2 B+i)(B+i)}-\frac{\left(\alpha_{2}-r\right) B}{i^{2} \sigma_{2}^{2}(B+i)}\right\}
$$

One can then use equation (37) in conjunction with the stock price index demand equation (33) and thereby show how the proportionate investment in the stock price index will be: ${ }^{23}$

$$
\gamma=-\frac{\left\{\left(\alpha_{2}-r\right)+B \log \left(\frac{g}{\mu}\right)\right\} \frac{e^{-i t} N}{W}}{W \sigma_{2}^{2}\left(-\frac{e^{-i t} N}{W^{2}}\right)}=\frac{\left(\alpha_{2}-r\right)+B \log \left(\frac{g}{\mu}\right)}{\sigma_{2}^{2}}
$$

Note that when the money to stock price ratio, $g(t)$, exceeds its long-run (that is, unconditional) mean, $\mu$, that the proportionate investment in the stock price index exceeds the proportionate investment in the stock price index compared with when the money to stock price ratio is below its long-run mean. This reflects the fact that the expected return on the stock price index is larger when $g(t)>\mu$ than it is when $g(t)<\mu$.This in turn will mean that the economic agent will have a greater incentive to invest in the stock price index when $g(t)>\mu$ than is the case when $g(t)<\mu$.

Now, in the appendix we demonstrate that the distributional properties of the proportionate investment in the stock price index can be determined by using equation (12) and equation (15) to show:

$$
\begin{aligned}
\frac{\left(\alpha_{2}-r\right)+B \log \left[\frac{g(t)}{\mu}\right]}{\sigma_{2}^{2}}= & e^{-B t}\left\{\frac{\left(\alpha_{2}-r\right)+B \log \left[\frac{g(0)}{\mu}\right]}{\sigma_{2}^{2}}\right\}+\left(1-e^{-B t}\right)\left\{\frac{\left(\alpha_{1}-\frac{1}{2} \sigma_{1}^{2}\right)-\left(r-\frac{1}{2} \sigma_{2}^{2}\right)}{\sigma_{2}^{2}}\right\} \\
& +\frac{B}{\sigma_{2}^{2}} \int_{0}^{t} e^{-B(t-s)} d z(s)
\end{aligned}
$$

Moreover, one can then use equation (38) to restate the above result in terms of the proportionate investment in the stock price index; namely:

$$
\gamma(t)=\gamma(0) e^{-B t}+\left\{\frac{\left(\alpha_{1}-\frac{1}{2} \sigma_{1}^{2}\right)-\left(r-\frac{1}{2} \sigma_{2}^{2}\right)}{\sigma_{2}^{2}}\right\}\left(1-e^{-B t}\right)+\frac{B}{\sigma_{2}^{2}} \int_{0}^{t} e^{-B(t-s)} d z(s)
$$

or upon subtracting $\gamma(0)$ from both sides of the above equation: ${ }^{24}$

$$
\gamma(t)-\gamma(0)=\left(1-e^{-B t}\right)\left\{\frac{\left(\alpha_{1}-\frac{1}{2} \sigma_{1}^{2}\right)-\left(r-\frac{1}{2} \sigma_{2}^{2}\right)}{\sigma_{2}^{2}}-\gamma(0)\right\}+\frac{B}{\sigma_{2}^{2}} \int_{0}^{t} e^{-B(t-s)} d z(s)
$$

This result shows that the proportionate investment in the stock price index evolves in terms of a mean reversion (that is, elastic random walk) process under which the proportionate investment in the stock price index gravitates towards an unconditional mean of $\frac{\left(\alpha_{1}-\frac{1}{2} \sigma_{1}^{2}\right)-\left(r-\frac{1}{2} \sigma_{2}^{2}\right)}{\sigma_{2}^{2}}$ with a restoring force that hinges on the speed of adjustment coefficient, $\left(1-e^{-B t}\right)$. Applying the expectation operator to equation (40a) will show that the proportionate investment in the stock price index evolves in terms of the Gaussian probability density with a mean which is a weighted average of the opening proportionate investment in the stock price index, $\gamma(0)$, and the unconditional mean of the proportionate investment in the stock price index, $\frac{\left(\alpha_{1}-\frac{1}{2} \sigma_{1}^{2}\right)-\left(r-\frac{1}{2} \sigma_{2}^{2}\right)}{\sigma_{2}^{2}}$, or:

$$
E[\gamma(t)]=\gamma(0) e^{-B t}+\left\{\frac{\left(\alpha_{1}-\frac{1}{2} \sigma_{1}^{2}\right)-\left(r-\frac{1}{2} \sigma_{2}^{2}\right)}{\sigma_{2}^{2}}\right\}\left(1-e^{-B t}\right)
$$

Here, it will be recalled that our empirical estimates of the speed of adjustment coefficient are remarkably small and lead to estimates of the half-life of the adjustment period which are of the order of fifteen years. This in turn 
will mean that in expectations, convergence of the proportionate investment in the stock price index towards its unconditional mean will be very slow. There will, of course, be stochastic perturbations associated with the rate at which the proportionate investment in the stock price index converges towards its long-run mean and the potential magnitude of these stochastic perturbations will be captured by the variance of the proportionate investment in the stock price index; namely:

$$
\operatorname{Var}[\gamma(t)]=\frac{B^{2} \sigma^{2}}{\sigma_{2}^{4}} e^{-2 B t} \int_{0}^{t} e^{2 B s} d s=\frac{B^{2}}{\sigma_{2}^{2}} \frac{\left(\sigma_{1}^{2}+\sigma_{2}^{2}-2 \rho_{12} \sigma_{1} \sigma_{2}\right)}{\sigma_{2}^{2}}\left(1-e^{-2 B t}\right)
$$

These results show that in the steady state (for which $t \rightarrow \infty$ ), the proportionate investment in the stock price index will evolve in terms of the Gaussian probability density with an unconditional mean of:

$$
E(\gamma)=\frac{\left(\alpha_{1}-\frac{1}{2} \sigma_{1}^{2}\right)-\left(r-\frac{1}{2} \sigma_{2}^{2}\right)}{\sigma_{2}^{2}}
$$

and an unconditional variance given by:

$$
\operatorname{Var}(\gamma)=\frac{B^{2}}{\sigma_{2}^{2}} \frac{\left(\sigma_{1}^{2}+\sigma_{2}^{2}-2 \rho_{12} \sigma_{1} \sigma_{2}\right)}{\sigma_{2}^{2}}
$$

One can provide an illustrative example of these results by recalling that the average annual rate of growth in the M2 monetary aggregate for the U.S. economy over the period from 1871 until 2018 amounts to $\alpha_{1}=6 \%$ per annum with a standard deviation of $\sigma_{1}=5.4 \%$. Similarly, the average annual return on the S\&P Composite Index (including dividends) over this period is $\alpha_{2}=8.7 \%$ per annum with a standard deviation of $\sigma_{2}=18 \%$. Finally, Shiller (2015) reports an average ten-year constant treasury bond rate of $r=5 \%$ per annum. One can use this average bond rate in conjunction with the previously summarised money and stock return statistics to estimate the steady state proportionate investment in the stock price index as:

$$
E(\gamma)=\frac{\left(\alpha_{1}-\frac{1}{2} \sigma_{1}^{2}\right)-\left(r-\frac{1}{2} \sigma_{2}^{2}\right)}{\sigma_{2}^{2}}=\frac{\left(0.06-\frac{1}{2} 0.054^{2}\right)-\left(0.05-\frac{1}{2} 0.18^{2}\right)}{0.18^{2}}=75 \%
$$

That is, in the steady state, an investor with Bernoulli preferences will hold about three-quarters of their wealth in the stock price index and about one-quarter in money.

Now, in section 4 our empirical analysis shows that the parameter $B$ is of the order of $0.035=3.5 \%$. Moreover, the covariance between the annual return on the S\&P Composite Index and the annual rate of growth in the M2 monetary aggregate over this period amounts to $\rho_{12} \sigma_{1} \sigma_{2}=0.16 \%$. It follows from these latter two statistics that the variance of the steady state proportionate investment in the stock price index can be estimated as:

$$
\operatorname{Var}(\gamma)=\frac{B^{2}}{\sigma_{2}^{2}} \frac{\left(\sigma_{1}^{2}+\sigma_{2}^{2}-2 \rho_{12} \sigma_{1} \sigma_{2}\right)}{\sigma_{2}^{2}}=\left(\frac{0.035}{0.18}\right)^{2}\left(\frac{0.054^{2}+0.18^{2}-2 \times 0.0016 \times 0.054 \times 0.18}{0.18^{2}}\right)=4.2 \%
$$

Moreover, for a steady state economy encompassing stable monetary policies it can be demonstrated that the money to stock price ratio will fluctuate randomly over a relatively narrow range around its unconditional expected value. One can illustrate this point by supposing the monetary authorities invoke the kind of stable monetary policy recommended by Friedman $(1962,54)$ - the so called 'Friedman $k$-percent rule' - under which 'the total stock of money ... rises month by month, and ... day by day, at an annual rate of $k \ldots$ where $k$ is somewhere between 3 and 5 [percent]'. This, in turn, implies that the variance of the rate of increase in the money supply will be $\sigma_{1}^{2}=0$, in which case the ceteris paribus estimate of the steady state proportionate investment in 
the stock price index based on our data covering the period from 1871 until 2018 turns out to be:

$$
E(\gamma)=\frac{\left(\alpha_{1}-r\right)}{\sigma_{2}^{2}}+\frac{1}{2}=\frac{0.06-0.05}{0.18^{2}}+\frac{1}{2}=81 \%
$$

Moreover, similar calculations show that the ceteris paribus estimate of the variance of the steady state proportionate investment in the stock price index amounts to:

$$
\operatorname{Var}(\gamma)=\frac{B^{2}}{\sigma_{2}^{2}}=\left(\frac{0.035}{0.18}\right)^{2}=3.8 \%
$$

Note how the steady state proportionate investment in the stock price index increases (from $75 \%$ to $81 \%$ of the economic agent's investment portfolio) and the steady state variance of the proportionate investment in the stock price index declines (from $4.2 \%$ to $3.8 \%$ ) reflecting the more stable monetary policy associated with the implementation of the Friedman $k$-percent rule. ${ }^{25}$

\section{Summary conclusions}

We investigate the implications of the Modern Quantity Theory of Money as developed by Friedman (1956) and others, for the nominal pricing of equity stocks. Our analysis is compatible with the hypothesis that the money to stock price ratio evolves in terms of an elastic (that is, mean reverting) random walk. Using annual U.S. data covering the period from 1871 until 2018 shows that the 'half-life' of the period it takes for the money to stock price ratio to converge towards its long-run mean is around fifteen years. Here, however, our empirical analysis also shows that excess monetary growth and the unexpected inflation associated with it, has a retrograde impact on the production and investment decisions implemented by firms and leads to an increase in the money to stock price ratio (equivalently, the stock price index falls relative to the M2 monetary aggregate).

Given this, the ability to hedge investment portfolios against adverse movements in asset prices associated with excess monetary growth will be of considerable value to firms and investors (Ross 1976; Cox and Rubinstein 1985, 428 et seq.). Moreover, one can use the Fundamental Theorem of Asset Pricing (Harrison and Kreps 1979; Harrison and Pliska 1981; Harrison and Pliska 1983; Kreps 1981) to determine the costs associated with such hedging procedures. The difficulty here, however, is that it is not at all clear how the dynamic tracking of the money to stock price ratio which is necessary for the hedging procedures implied by the Fundamental Theorem of Asset Pricing, can be implemented. Hence, an important focus for future research involves determining how these hedging procedures might work and then, how they might be used in conjunction with the Fundamental Theorem of Asset Pricing to evaluate the costs associated with any given hedging procedure.

Our analysis also presents a framework for determining how economic agents ought to rebalance their investment portfolios in response to disequilibria in the money to stock price ratio and thereby maximise the expected discounted utility associated with their future consumption. Here, Bernoulli preferences show that the economic agent will hold a greater proportion of their wealth in the stock price index when the money to stock price ratio is relatively large. A useful extension would assess the sensitivity of these results to alternative specifications of the preference function - in particular, the HARA (hyperbolic absolute risk aversion) preference functions that have formed such an integral part of developments in theoretical finance (Ingersoll 1987, 39-41).

\section{Notes}

1. The importance of this issue cannot be overstated, especially in light of the monetary policy pursued by the Bank of England which involves a programme of quantitative easing that has pumped a total $£ 895$ billion of cash into the UK economy over the period between November, 2009 and November, 2020 (https://www.bankofengland.co.uk/monetary-policy/quantitative-easing). Similarly, as part of its response to the Global Financial Crisis (GFC), in 2008 the U.S. Federal Reserve also initiated a programme of quantitative easing. Four such programmes involving a $\$ 4$ trillion injection of cash into the U.S. economy have been implemented, the latest of which began on 15 March, 2020 with a plan to pump over $\$ 700$ billion into the U.S. economy in response to the economic shutdown induced by the COVID-19 pandemic 
(https://www.federalreserve.gov/newsevents/pressreleases/monetary20200315a.htm). Japan, Switzerland and Sweden amongst many other countries have also implemented monetary policies involving quantitative easing.

2. There is an ongoing debate over the appropriate definition of 'money' which ought to be applied in empirical analysis of the kind summarised here (Barnett 1980; Barnett 2012). We use M2 as the monetary base in our empirical analysis because it was Friedman's preferred measure of the money supply (Nelson 2007, 173; Lim and Sriram 2003, 10). We also follow other studies in using the S\&P Composite Index as the comprehensive index of stock prices (Friedman 1988).

3. There is now a long and voluminous literature which shows, under conditions of low-to-moderate inflation, that there is a negative relationship between stock returns and unexpected inflation. Exemplar papers include Bodie 1976; Fama and Schwert 1977; Fama 1981; Kaul 1987; Barnes, Boyd, and Smith 1999; Campbell and Vuolteenaho 2004; Lee 2010 and Valcarcel 2012 all of whom summarise empirical analysis which is compatible with the hypothesis that there is a negative relationship between stock returns and unexpected inflation. See Lee, Tang, and Wong 2000 and Zhao 2017 for a summary of the literature dealing with stock returns under hyperinflationary conditions.

4. Considerations of space mean that we can here provide only a skeletal summary of the Modern Quantity Theory of Money. A comprehensive summary of the literature in this area is to be found in Teles, Uhlig, and Valle e Azevedo (2016), Wang (2017) and chapter 20 of Mishkin (2019).

5. In subsequent analysis we follow Modigliani and Miller $(1958,268)$ in assuming 'All bonds ... yield a constant income per unit of time, and this income is regarded as certain by all traders regardless of the issuer'; that is, the infinitesimal return on all bonds, $r_{b}$, is taken to be the risk-free rate of return.

6. Makinen $(1977,240)$ notes how 'empirical studies have shown that the yield on human capital generally exceeds the yield on non-human capital.' This, in turn, will mean that the 'return sacrificed by holding cash is greater when the alternative is human wealth rather than nonhuman wealth. Thus, when the individual's wealth is concentrated in human form, it ought to reduce the quantity of money demanded. For these reasons Friedman introduces the ratio of nonhuman to human wealth as a variable in the demand function [for money]. It is approximated by the ratio of income from nonhuman wealth to income from human wealth.'

7. One can also apply Itô's formula to equation (9) and thereby show that infinitesimal increments in the logarithmic return on the stock price index over the period from time zero to time $t$, has the following representation:

$$
d \log \left[\frac{P(t)}{P(0)}\right]=\frac{d P(t)}{P(t)}-\frac{1}{2}\left\{\frac{d P(t)}{P(t)}\right\}^{2}=\left\{\left(\alpha_{2}-\frac{1}{2} \sigma_{2}^{2}\right)+B \log \left(\frac{g(t)}{\mu}\right)\right\} d t+d z_{2}(t)
$$

Applying the expectation operator to the above expression shows that the expected infinitesimal increment in the logarithmic return on the stock price index is given by:

$$
E\left\{d \log \left[\frac{P(t)}{P(0)}\right]\right\}=\left\{\left(\alpha_{2}-\frac{1}{2} \sigma_{2}^{2}\right)+B \log \left(\frac{g(t)}{\mu}\right)\right\} d t
$$

A similar application of the expectation operator also shows that the variance of infinitesimal increments in the logarithmic return on the stock price index amounts to $\operatorname{Var}\left\{d \log \left[\frac{P(t)}{P(0)}\right]\right\}=\sigma_{2}^{2} d t$.

8. A simple application of L'Hôpital's Rule shows when $t \rightarrow 0$ :

$$
\begin{aligned}
\lim _{t \rightarrow 0} \frac{E\left\{\log \left[\frac{P(t)}{P(0)}\right]\right\}}{t} & =\lim _{t \rightarrow 0} \frac{\left(1-e^{-B t}\right)}{t}\left[\log \left(\frac{g(0)}{\mu}\right)-\frac{\left(2 \alpha_{1}-\sigma_{1}^{2}\right)-\left(2 \alpha_{2}-\sigma_{2}^{2}\right)}{2 B}\right]+\left(\alpha_{1}-\frac{1}{2} \sigma_{1}^{2}\right) \\
& =\left(\alpha_{2}-\frac{1}{2} \sigma_{2}^{2}\right)+B \log \left(\frac{g(0)}{\mu}\right)
\end{aligned}
$$

a result which is compatible with equation (9) of the text.

9. Again, L'Hôpital's Rule shows when $t \rightarrow 0$ :

$$
\lim _{t \rightarrow 0} \frac{\operatorname{Var}\left\{\log \left[\frac{P(t)}{P(0)}\right]\right\}}{t}=\sigma_{1}^{2}-\frac{2 \sigma_{1}^{2}-2 \rho_{12} \sigma_{1} \sigma_{2}}{B} \lim _{t \rightarrow 0} \frac{\left(1-e^{-B t}\right)}{t}+\frac{\sigma_{1}^{2}+\sigma_{2}^{2}-2 \rho_{12} \sigma_{1} \sigma_{2}}{2 B} \lim _{t \rightarrow 0} \frac{\left(1-e^{-2 B t}\right)}{t}
$$

or equivalently:

$$
\lim _{t \rightarrow 0} \frac{\operatorname{Var}\left\{\log \left[\frac{P(t)}{P(0)}\right]\right\}}{t}=\sigma_{1}^{2}-\left(2 \sigma_{1}^{2}-2 \rho_{12} \sigma_{1} \sigma_{2}\right)+\left(\sigma_{1}^{2}+\sigma_{2}^{2}-2 \rho_{12} \sigma_{1} \sigma_{2}\right)=\sigma_{2}^{2}
$$

a result which is again, compatible with equation (9) of the text.

10. The data employed in our empirical analysis were downloaded from Appendix B of Gordon (1986), the website http://www.econ.yale.edu/ shiller/data.htm which accompanies Shiller (2015) and the Federal Reserve Board of St. Louis website. 
11. Note that in the 'steady state', the mean and variance of the logarithmic variation in the money to stock price ratio are given by:

$$
\lim _{t \rightarrow \infty} E\left\{\log \left[\frac{g(t)}{g(0)}\right]\right\}=\lim _{t \rightarrow \infty}\left(1-e^{-B t}\right)\left\{\frac{2 A-\sigma^{2}}{2 B}-\log \left[\frac{g(0)}{\mu}\right]\right\}=\frac{2 A-\sigma^{2}}{2 B}-\log \left[\frac{g(0)}{\mu}\right]
$$

and:

$$
\lim _{t \rightarrow \infty} \operatorname{Var}\left\{\log \left[\frac{g(t)}{g(0)}\right]\right\}=\lim _{t \rightarrow \infty} \frac{\sigma^{2}}{2 B}\left(1-e^{-2 B t}\right)=\frac{\sigma^{2}}{2 B}
$$

respectively. This has the important implication that for $B>0$, the logarithmic variation in the money to stock price ratio evolves in terms of a stationary normal probability density. See Lucas (2000) for a discussion of the importance of steady state solutions in this area of the literature.

12. Friedman $(1959,611)$ notes how a major policy implication of the Modern Quantity Theory of Money is an inability to predict at all accurately a [given monetary] relation over very short periods, from month to month, quarter to quarter, even year to year.' One can illustrate this point in the present context by using equation (19) and equation (20) to show that the Coefficient of Variation for the money to stock price ratio is given by:

$$
\frac{\sqrt{\operatorname{Var}\left\{\log \left[\frac{g(t)}{g(0)}\right]\right\}}}{E\left\{\log \left[\frac{g(t)}{g(0)}\right]\right\}}=\frac{\sigma}{\sqrt{2 B}\left\{\frac{2 A-\sigma^{2}}{2 B}-\log \left[\frac{g(0)}{\mu}\right]\right\}} \sqrt{\frac{1+e^{-B t}}{1-e^{-B t}}}
$$

This shows that the Coefficient of Variation asymptotically declines towards a limiting value of:

$$
\lim _{t \rightarrow \infty} \frac{\sqrt{\operatorname{Var}\left\{\log \left[\frac{g(t)}{g(0)}\right]\right\}}}{E\left\{\log \left[\frac{g(t)}{g(0)}\right]\right\}}=\frac{\sigma}{\sqrt{2 B}\left\{\frac{2 A-\sigma^{2}}{2 B}-\log \left[\frac{g(0)}{\mu}\right]\right\}}
$$

This in turn means there is relatively less noise in the relationship between $\log [g(t)]$ and $\log [g(0)]$ for larger values of ' $t$ '. The use of the annual $(t=1)$ data employed in our empirical analysis represents a compromise between the reduction in noise which comes from using a larger value of $t$ (equivalently, a smaller sample size) and the consistency of parameter estimation which comes from using a smaller value of $t$ (equivalently, a larger sample size) (Freeman 1963, 234-236).

13. A note of caution is in order here. One can apply L'Hôpital's Rule to equation (20) and thereby show:

$$
\lim _{B \rightarrow 0} \operatorname{Var}\left\{\log \left[\frac{g(t)}{g(0)}\right]\right\}=\lim _{B \rightarrow 0} \frac{\sigma^{2}}{2 B}\left(1-e^{-2 B t}\right)=\sigma^{2} t
$$

It follows from this that when $B=0$, the logarithmic variation in the money to stock price ratio (as formalised by equation (18)) evolves in terms of a Wiener process with variance parameter $\sigma^{2}$ and therefore, is non-stationary (Hoel, Port, and Stone $1987,123)$. This, in turn, has the important implication that a $t$-score of the magnitude given here is not sufficient at most conventional levels of statistical significance, to reject the null hypothesis of a unit root (equivalently, $B=0$ ) in the stochastic process describing the evolution of the logarithm of the money to stock price ratio (Dickey and Fuller 1979). This issue is addressed in further detail in section 5 below.

14. We replicated the empirical results summarised in Table 1 by using the output to stock price ratio as the dependent variable in our regression equation (18) in place of the money to stock price ratio. Now, here it will be recalled that the Quantity Theory of Money requires that $M V=Y$ (where $M$ is the money supply, $V$ is the velocity of circulation and $Y$ is the nominal value of output). Output is approximated by the annual Gross National Product (GNP) for the US economy. Note that the Quantity Theory of Money implies that the output to stock price ratio $\left(\frac{Y}{P}\right)$ is equivalent to $\left(\frac{M}{P}\right) V$. In other words, using output in place of money in our regression equations is equivalent to 'weighting' the money to stock price ratio in each year by the velocity of circulation for that year. The empirical results using $\left(\frac{M}{P}\right) V$ as the dependent variable are almost identical to those summarised in Table 1 based on the 'unweighted' independent variable, $\left(\frac{M}{P}\right)$ - the one exception being that the Durbin-Watson statistic for the $\left(\frac{M}{P}\right) V$ data amounts to 2.1008 as compared to 1.9798 for the unweighted $\left(\frac{M}{P}\right)$ data summarised in Table 1 . Neither of these Durbin-Watson statistics differ from their expected value of $E(d) \approx 2$ at all conventional levels of statistical significance (Savin and White 1977).

15. Fisher (1922), Fisher (1928), Cagan (1956), Lucas (1980), Carlton (1982) and more latterly, Higson, Shinozawa, and Tippett (2007) amongst others, provide international historical evidence of the pernicious effects that unexpected inflation can, and has had, on the production and investment decisions implemented by firms.

16. The welfare costs associated with inflation are normally determined by summing the consumer surpluses which arise from asset holdings at different levels of inflation. Varian (1984, 263-278) summarises the relevant theory and Lucas (2000) provides a survey and empirical estimates of the welfare costs arising from inflation for the United States. Lucas (2000, 271) concludes that 'in all of the models I have reviewed, the estimated gains of reducing inflation and interest rates are positive, starting from any interest rate above, say, one tenth of one percent.' 
17. Here, one can apply L'Hôpital's Rule and thereby show:

$$
\lim _{t \rightarrow 0} \frac{2\left(1-e^{-B t}\right)}{B t\left(1+e^{-B t}\right)}=\lim _{t \rightarrow 0} \frac{2 B e^{-B t}}{B\left(1+e^{-B t}\right)-B^{2} t e^{-B t}}=1
$$

It follows from this that:

$$
\lim _{t \rightarrow 0} \rho \sqrt{\frac{2\left(1-e^{-B t}\right)}{B t\left(1+e^{-B t}\right)}}=\rho
$$

which, as required, is the infinitesimal correlation coefficient between the white noise process, $d z(t)$, in equation (18) and the white noise process, $d \eta(t)$, in equation (21).

18. Applying L'Hôpital's Rule to equation (26) shows:

$$
\lim _{B \rightarrow 0} \operatorname{Var}\left\{\log \left[\frac{g(t)}{g(0)}\right]\right\}=\lim _{B \rightarrow 0} \frac{\sigma^{2}}{2 B}\left\{1-\frac{2 \rho^{2}\left(1-e^{-B t}\right)}{B t\left(1+e^{-B t}\right)}\right\}\left(1-e^{-2 B t}\right)=\left(1-\rho^{2}\right) \sigma^{2} t
$$

in which case it follows when $B=0$, the logarithmic variation in the money to stock price ratio (as formalised by equation (24)), evolves in terms of a Wiener process with variance parameter $\left(1-\rho^{2}\right) \sigma^{2} t$ and therefore, is non-stationary (Hoel, Port, and Stone 1987, 123). Given this, it is important to note that the Covariate Augmented Dickey-Fuller Test (Hansen 1995) returns an empirically estimated 'nuisance parameter' for our data of $\rho^{2}=0.8895$ and a CADF $t$ statistic of -4.2399 . The table provided by Hansen $(1995,1155)$ shows a CADF $t$ statistic of this magnitude implies that the (asymptotic) probability of a unit root (equivalently, $B=0$ ) in the coefficient for the logarithm of the money to stock price ratio is much less than $1 \%$.

19. We again replicated the empirical results summarised in Table 2 by using the output to stock price ratio as the dependent variable in our regression analysis in place of the money to stock price ratio. Output is again approximated by the annual Gross National Product (GNP) for the US economy. The empirical results using the output to stock price ratio as the dependent variable are almost identical to those summarised in Table 2 based on the money to stock price ratio - the one exception being that the Durbin-Watson statistics for the output to stock price ratio data amounts to 2.1479 as compared to 2.0141 for the unweighted money to stock price ratio data summarised in Table 2. Neither of these Durbin-Watson statistics differ from their expected value of $E(d) \approx 2$ at all conventional levels of statistical significance (Savin and White 1977).

20. One could develop previous analysis to include inflation as a component of the Hamilton-Jacobian-Bellman equation. However, this requires a much more complicated development of the Hamilton-Jacobi-Bellman equation than can be given here. Given this, the analysis summarised in this section can be interpreted as determining the impact that variations in the money to stock price ratio have on the portfolio investment decisions made by economic agents in a low and stable inflationary environment.

21. The Hessian matrix associated with the stationary point given here is $\left[\begin{array}{cc}e^{-i t} U^{\prime \prime}(C) & 0 \\ 0 & W^{2} \sigma_{2}^{2} \frac{\partial^{2} H}{\partial W^{2}}\end{array}\right]$. Since standard consumer theory dictates that $U^{\prime \prime}(C)<0$ and $\frac{\partial^{2} H}{\partial W^{2}}<0$ (Varian 1984), it follows that both eigenvalues of the Hessian matrix are negative. This in turn means that the stationary point represents a maximum of the Hamilton-Jacobi-Bellman equation (Apostol 1969, $311)$.

22. There is a natural boundary along the line $g=\mu$ for which this solution encompasses the initial condition $H(W, g, t)=$ $H(W, \mu, 0)=J+N \log (W)$ and under which, the partial differential equation (36) will represent a well-posed initial value problem (O’Neil 1987, 849).

23. It will also be recalled how the envelope condition (32) shows that infinitesimal consumption may be determined from the expression $C=e^{-i t}\left\{\frac{\partial H}{\partial W}\right\}^{-1}$.Now, differentiating through equation (37) shows $\frac{\partial H}{\partial W}=\frac{e^{-i t}}{i W}$. This in turn implies $C=$ $e^{-i t}\left\{\frac{e^{-i t}}{i W}\right\}^{-1}=i W$. Thus under Bernoulli preferences, consumption is a fixed proportion of wealth - where the constant of proportionality is given by the own rate of discount, $i$ (Friedman 1957).

24. Applying L'Hôpital's Rule shows when $t \rightarrow 0$ :

$$
\lim _{t \rightarrow 0} \frac{\gamma(t)-\gamma(0)}{t}=\lim _{t \rightarrow 0} \frac{\left(1-e^{-B t}\right)}{t}\left\{\frac{\left(\alpha_{1}-\frac{1}{2} \sigma_{1}^{2}\right)-\left(r-\frac{1}{2} \sigma_{2}^{2}\right)}{\sigma_{2}^{2}}-\gamma(0)\right\}+\lim _{t \rightarrow 0}\left\{\frac{B}{\sigma_{2}^{2}} \frac{\int_{0}^{t} e^{-B(t-s)} d z(s)}{t}\right\}
$$

or that the proportionate investment in the stock price index evolves in terms of the following stochastic differential equation:

$$
d \gamma(t)=B\left\{\frac{\left(\alpha_{1}-\frac{1}{2} \sigma_{1}^{2}\right)-\left(r-\frac{1}{2} \sigma_{2}^{2}\right)}{\sigma_{2}^{2}}-\gamma(t)\right\} d t+\frac{B}{\sigma_{2}^{2}} d z(t)
$$

This characterises the proportionate investment in the stock price index as evolving in terms of an Uhlenbeck and Ornstein (1930) (or elastic random walk) process with an unconditional mean of $\frac{\left(\alpha_{1}-\frac{1}{2} \sigma_{1}^{2}\right)-\left(r-\frac{1}{2} \sigma_{2}^{2}\right)}{\sigma_{2}^{2}}$ and a speed of adjustment coefficient of $B$. 
25. From equation (43) we have $\frac{\partial E(\gamma)}{\partial \sigma_{1}}=-\sigma_{1}<0$, so that as $\sigma_{1}$ increases in magnitude, $E(\gamma)$ declines in magnitude and visa versa. Similarly, from equation (44) we have $\frac{\partial \operatorname{Var}(\gamma)}{\partial \sigma_{1}}=\frac{2 B^{2}}{\sigma_{2}^{2}} \frac{\left(\sigma_{1}-\rho_{12} \sigma_{2}\right)}{\sigma_{2}^{2}}$ so that if $\left(\sigma_{1}-\rho_{12} \sigma_{2}\right)<0$, then $\operatorname{Var}(\gamma)$ decreases as $\left(\rho_{12} \sigma_{2}-\sigma_{1}\right)$ increases in magnitude and vice versa.

\section{Acknowledgement}

We owe an immeasurable debt to Brin Mark, who was always a quantity theorist. The authors also gratefully acknowledge the constructive comments and suggestions of the Editor and referees.

\section{Disclosure statement}

No potential conflict of interest was reported by the author(s).

\section{Notes on contributors}

Xiaojing Song has published papers which investigate the role that cultural disparity plays in cross-border takeovers; alternative stochastic process for modelling asset prices and the impact they have on abnormal return calculations; the empirical validity of the Fama and French Asset Pricing Model and, the calculation of logarithmic returns under Constant Elasticity of Variance stochastic processes.

Thu Phuong Truong has published papers in the fields of financial regulation, corporate governance, corporate disclosure, corporate strategy, and firm valuation. Among her recent works are continuous disclosure: Are Friday announcements special in a continuous disclosure environment (Accounting \& Finance, Vol. 61, 2021) and stock trading behaviour: Stock trading behaviour and firm performance: Do CEO equity-based compensation and block ownership matter? (Pacific-Basin Finance Journal, Vol. 66, 2021).

Mark Tippett has published papers which apply the methods of numerical mathematics to assess the accuracy and reliability of information summarized in corporate financial statements. He has also combined numerical mathematics with the theory of stochastic processes to estimate the convex relationship which exists between the market value of equity on the one hand and current earnings and the book value of equity on the other. Much of his research work in these areas has been summarized in his book entitled Principles of Equity Valuation (Routledge, 2012).

John van der Burg has published papers on stochastic processes applied to finance with a particular focus on models to describe and predict cash flows and cash holdings. His most recent paper on this topic is entitled "A Hyperbolic Model of Optimal Cash Balances" and was published in the European Journal of Finance.

\section{References}

Apostol, T. 1969. Calculus, Volume II. New York: Wiley.

Arnold, L. 1974. Stochastic Differential Equations: Theory and Applications. New York: Wiley.

Barndorff-Nielsen, O., and N. Shephard. 2001. "Non-Gaussian Ornstein-Uhlenbeck Based Models and Some of Their Uses in Financial Economics." Journal of the Royal Statistical Society. Series B (Statistical Methodology) 63 (2): 167-241.

Barnes, M., J. Boyd, and B. Smith. 1999. "Inflation and Asset Returns.” European Economic Review 43 (4-6): 737-754.

Barnett, W. 1980. "Economic Monetary Aggregates: an Application of Index Number and Aggregation Theory." Journal of Econometrics 14 (1): 11-48.

Barnett, W. 2012. Getting it Wrong: How Faulty Monetary Statistics Undermine the Fed, the Financial System, and the Economy. Cambridge, Massachusetts: MIT Press.

Batini, N., and E. Nelson. 2002. The lag from monetary policy actions to inflation: Friedman revisited. Bank of England External Monetary Policy Committee Unit. Discussion Paper \#6.

Bernoulli, D. 1954. "Exposition of a new Theory on the Measurement of Risk." Econometrica 22 (1): 23-36.

Bodie, Z. 1976. “Common Stock as a Hedge Against Inflation.” Journal of Finance 31 (2): 459-470.

Cagan, P. 1956. The Monetary Dynamics of Hyperinflation, in Studies in the Quantity Theory of Money, ed. M. Friedman. Chicago: University of Chicago Press.

Cagan, P. 1972. The Channels of Monetary Effects on Interest Rates. New York: Columbia University Press.

Campbell, J., and T. Vuolteenaho. 2004. "Inflation Illusion and Stock Prices." American Economic Review 94 (2): 19-23.

Carlton, D. 1982. The Disruptive Effect of Inflation on the Organization of Markets, in Inflation: Causes and Effects, ed. R. Hall. Chicago: National Bureau of Economic Research.

Cox, J., and M. Rubinstein. 1985. Option Markets. Englewood Cliffs, New Jersey: Prentice-Hall, Inc.

Dickey, D., and W. Fuller. 1979. "Distribution of the Estimators for Autoregressive Time Series with a Unit Root." Journal of the American Statistical Association 74 (366): 427-431.

Fama, E. 1981. “Stock Returns, Real Activity, Inflation, and Money." American Economic Review 71 (4): $545-565$. 
Fama, E., and G. Schwert. 1977. “Asset Returns and Inflation.” Journal of Financial Economics 5 (2): 115-146.

Fisher, I. 1922. The Purchasing Power of Money. New York: MacMillan.

Fisher, I. 1928. The Money Illusion. New York: Adelphi Company.

Freeman, H. 1963. Introduction to Statistical Inference. Reading Massachusetts: Addison-Wesley Publishing Company, Inc.

Friedman, M. 1956. The Quantity Theory of Money - A Restatement, in Studies in the Quantity Theory of Money, ed. M. Friedman. Chicago: University of Chicago Press.

Friedman, M. 1957. A Theory of the Consumption Function. Princeton: Princeton University Press.

Friedman, M. 1959. Employment, Growth and Price Level. Report to the Joint Economic Committee, 86th Congress, 1st Session.

Friedman, M. 1962. Capitalism and Freedom. Chicago: University of Chicago Press.

Friedman, M. 1970. “A Theoretical Framework for Monetary Analysis.” Journal of Political Economy 78 (2): $193-238$.

Friedman, M. 1977. "Nobel Lecture: Inflation and Unemployment.” Journal of Political Economy 85 (3): $451-472$.

Friedman, M. 1988. "Money and the Stock Market." Journal of Political Economy 96 (2): 221-245.

Gibson, R., and E. Schwartz. 1990. "Stochastic Convenience Yield and the Pricing of oil Contingent Claims." Journal of Finance 45 (3): 959-976.

Gordon, R.1986. The American Business Cycle: Continuity and Change. Chicago: University of Chicago Press.

Greene, W. 2019. Econometric Analysis. Global Edition. Harlow, Essex: Pearson Education.

Hansen, B. 1995. "Rethinking the Univariate Approach to Unit Root Testing." Econometric Theory 11 (5): $1148-1171$.

Harrison, J., and D. Kreps. 1979. "Martingales and Arbitrage in Multi-Period Securities Markets." Journal of Economic Theory 20 (3): 381-408.

Harrison, J., and S. Pliska. 1981. "Martingales and Stochastic Integrals in the Theory of Continuous Trading." Stochastic Processes and Their Applications 11 (3): 215-260.

Harrison, J., and S. Pliska. 1983. "A Stochastic Model of Continuous Trading: Complete Markets." Stochastic Processes and Their Applications 15 (3): 313-316.

Higson, A., Y. Shinozawa, and M. Tippett. 2007. "IAS 29 and the Cost of Holding Money under Hyperinflationary Conditions." Accounting and Business Research 37 (2): 97-121.

Hoel, P., S. Port, and C. Stone. 1987. Introduction to Stochastic Processes. Long Grove, Illinois: Waveland Press, Inc.

Hong, K., and S. Satchell. 2012. “Defining Single Asset Price Momentum in Terms of a Stochastic Process." Theoretical Economics Letters 2 (3): 274-277.

Ingersoll, J. 1987. Theory of Financial Decision Making. Lanham, Maryland: Rowman and Littlefield Publishing Group. Inc.

Karlin, S., and H. Taylor. 1981. A Second Course in Stochastic Processes. New York: Academic Press.

Kaul, G. 1987. "Stock Returns and Inflation: The Role of the Monetary Sector." Journal of Financial Economics 18 (2): $253-276$.

Kreps, D. 1981. “Arbitrage and Equilibrium in Economics with Infinitely Many Commodities.” Journal of Mathematical Economics 8 (1): 15-35.

Kumhof, M., and S. Van Nieuwerburgh. 2002. A Fiscal theory of the currency risk premium and of sterilized intervention. IMF Working Paper. WP02/09.

Lee, B. 2010. "Stock Returns and Inflation Revisited: An Evaluation of the Inflation Illusion Hypothesis." Journal of Banking and Finance 34 (6): 1257-1273.

Lee, S., D. Tang, and K. Wong. 2000. “Stock Returns During the German Hyperinflation.” Quarterly Review of Economics and Finance 40 (3): 375-386.

Lim, E.-G., and S. Sriram. 2003. Factors underlying the definitions of broad money: An examination of recent U.S. monetary statistics and practices of other countries. IMF Working Paper. WP03/62.

Lucas, R. 1980. “Two Illustrations of the Quantity Theory of Money.” American Economic Review 70 (5): $1005-1014$.

Lucas, R. 1996. “Nobel Lecture: Monetary Neutrality.” Journal of Political Economy 104 (4): 661-682.

Lucas, R. 2000. "Inflation and Welfare." Econometrica 68 (2): 247-274.

Makinen, G. 1977. Money, The Price Level, and Interest Rates. Englewood Cliffs, New Jersey: Prentice-Hall, Inc.

Merton, R. 1969. "Lifetime Portfolio Selection Under Uncertainty: The Continuous-Time Case." Review of Economics and Statistics 51 (3): 247-257.

Mishkin, F. 2019. Economics of Money, Banking and Financial Markets. New York: Pearson.

Modigliani, F., and M. Miller. 1958. “The Cost of Capital, Corporate Finance and the Theory of Finance." American Economic Review XLVIII (3): 261-297.

Nelson, E. 2007. “Milton Friedman and U.S. Monetary History: 1961-2006.” Federal Reserve Bank of St. Louis Review 89 (3): $153-182$.

O’Neil, P. 1987. Advanced Engineering Mathematics. Belmont, California: Wadsworth Publishing Company.

Patinkin, D. 1972. Studies in Monetary Economics. New York: Harper and Row.

Polyanin, A., and V. Zaitsev. 2012. Handbook of Non-Linear Partial Differential Equations. London: CRC Press.

Rhys, H., and M. Tippett. 1993. “On the Steady State Properties of Financial Ratios.” Accounting and Business Research 23 (92): $500-510$

Ross, S. 1976. “Options and Efficiency.” Quarterly Journal of Economics 90 (1): 75-89.

Savin, N., and K. White. 1977. “The Durbin-Watson Test for Serial Correlation with Extreme Sample Sizes or Many Regressors.” Econometrica 45 (8): 1989-1996.

Shiller, R. 2015. Irrational Exuberance. Princeton: Princeton University Press.

Teles, P., H. Uhlig, and J. Valle e Azevedo. 2016. “Is Quantity Theory Still Alive?” Economic Journal 126 (591): $442-464$. 
Tippett, M. 1990. “An Induced Theory of Financial Ratios." Accounting and Business Research 21 (81): 77-85.

Uhlenbeck, G., and L. Ornstein. 1930. "On the Theory of the Brownian Motion.” Physical Review 36 (5): 823-841.

Valcarcel, V. 2012. "The Dynamic Adjustments of Stock Prices to Inflation Disturbances." Journal of Economics and Business 64 (2): $117-144$.

Varian, H. 1984. Microeconomic Analysis. New York: Norton.

Wang, X. 2017. The Quantity Theory of Money: An empirical and quantitative reassessment. Working Paper, Department of Economics, Washington University in St. Louis.

Zhao, L. 2017. "Stock Returns Under Hyperinflation: Evidence from China 1945-48." China Economic Review 45 (1): 155-167.

\section{Appendix: Proportionate investment in the stock price index}

From equation (12) of the text we have:

$$
x(t)=\frac{\sqrt{2 B}}{\sigma} \log \left[\frac{g(t)}{\mu}\right]+\frac{\sigma}{\sqrt{2 B}}-\frac{2 A}{\sigma \sqrt{2 B}}
$$

whilst equation (15) of the text shows that $\mathrm{x}(\mathrm{t})$ evolves in terms of the following process:

$$
x(t)=x(0) e^{-B t}+\frac{\sqrt{2 B}}{\sigma} \int_{0}^{t} e^{-B(t-s)} d z(s)
$$

Substituting equation (12) into equation (15) will then show:

$$
\log \left[\frac{g(t)}{\mu}\right]+\frac{\sigma^{2}}{2 B}-\frac{A}{B}=\left\{\log \left[\frac{g(0)}{\mu}\right]+\frac{\sigma^{2}}{2 B}-\frac{A}{B}\right\} e^{-B t}+\int_{0}^{t} e^{-B(t-s)} d z(s)
$$

or equivalently:

$$
B \log \left[\frac{g(t)}{\mu}\right]=e^{-B t} B \log \left[\frac{g(0)}{\mu}\right]-\left(1-e^{-B t}\right)\left(\frac{1}{2} \sigma^{2}-A\right)+B \int_{0}^{t} e^{-B(t-s)} d z(s)
$$

where from equations (10) and equation (11) of the text respectively, $A=\left(\alpha_{1}-\alpha_{2}+\sigma_{2}^{2}-\rho_{12} \sigma_{1} \sigma_{2}\right)$ and $\sigma^{2}=\left(\sigma_{1}^{2}+\sigma_{2}^{2}\right.$ $-2 \rho_{12} \sigma_{1} \sigma_{2}$ ). It then follows:

$$
\frac{1}{2} \sigma^{2}-A=\left(\alpha_{2}-\frac{1}{2} \sigma_{2}^{2}\right)-\left(\alpha_{1}-\frac{1}{2} \sigma_{1}^{2}\right)
$$

and:

$$
\left(\alpha_{2}-r\right)+B \log \left[\frac{g(t)}{\mu}\right]=\left(\alpha_{2}-r\right)+e^{-B t} B \log \left[\frac{g(0)}{\mu}\right]-\left(1-e^{-B t}\right)\left\{\left(\alpha_{2}-\frac{1}{2} \sigma_{2}^{2}\right)-\left(\alpha_{1}-\frac{1}{2} \sigma_{1}^{2}\right)\right\}+B \int_{0}^{t} e^{-B(t-s)} d z(s)
$$

Adding and subtracting $e^{-B t}\left(\alpha_{2}-r\right)$ to the right-hand side of the above expression will then show:

or equivalently:

$$
\begin{gathered}
\left(\alpha_{2}-r\right)+B \log \left[\frac{g(t)}{\mu}\right]=e^{-B t}\left\{\left(\alpha_{2}-r\right)+B \log \left[\frac{g(0)}{\mu}\right]\right\}+\left(1-e^{-B t}\right)\left(\alpha_{2}-r\right) \\
-\left(1-e^{-B t}\right)\left\{\left(\alpha_{2}-\frac{1}{2} \sigma_{2}^{2}\right)-\left(\alpha_{1}-\frac{1}{2} \sigma_{1}^{2}\right)\right\}+B \int_{0}^{t} e^{-B(t-s)} d z(s)
\end{gathered}
$$

$$
\begin{gathered}
\left(\alpha_{2}-r\right)+B \log \left[\frac{g(t)}{\mu}\right]=e^{-B t}\left\{\left(\alpha_{2}-r\right)+B \log \left[\frac{g(0)}{\mu}\right]\right\} \\
-\left(1-e^{-B t}\right)\left\{\left(r-\frac{1}{2} \sigma_{2}^{2}\right)-\left(\alpha_{1}-\frac{1}{2} \sigma_{1}^{2}\right)\right\}+B \int_{0}^{t} e^{-B(t-s)} d z(s)
\end{gathered}
$$

One can then divide both sides of the above equation by $\sigma_{2}^{2}$ in which case we have equation (39) of the text, namely:

$$
\frac{\left(\alpha_{2}-r\right)+B \log \left[\frac{g(t)}{\mu}\right]}{\sigma_{2}^{2}}=e^{-B t}\left\{\frac{\left(\alpha_{2}-r\right)+B \log \left[\frac{g(0)}{\mu}\right]}{\sigma_{2}^{2}}\right\}+\left(1-e^{-B t}\right)\left\{\frac{\left(\alpha_{1}-\frac{1}{2} \sigma_{1}^{2}\right)-\left(r-\frac{1}{2} \sigma_{2}^{2}\right)}{\sigma_{2}^{2}}\right\}+\frac{B}{\sigma_{2}^{2}} \int_{0}^{t} e^{-B(t-s)} d z(s)
$$

